\title{
The Demography of Youth in Developing Countries and its Economic Implications
}

\author{
David Lam \\ Department of Economics and Population Studies Center \\ University of Michigan \\ Ann Arbor, MI 48106 \\ davidl@umich.edu
}

World Bank Policy Research Working Paper 4022, October 2006

The Policy Research Working Paper Series disseminates the findings of work in progress to encourage the exchange of ideas about development issues. An objective of the series is to get the findings out quickly, even if the presentations are less than fully polished. The papers carry the names of the authors and should be cited accordingly. The findings, interpretations, and conclusions expressed in this paper are entirely those of the authors. They do not necessarily represent the view of the World Bank, its Executive Directors, or the countries they represent. Policy Research Working Papers are available online at http://econ.worldbank.org. 


\section{Introduction}

Youth in developing countries find themselves in the midst of rapid social and economic change. As documented in the recent National Academy of Sciences report on transitions to adulthood in developing countries (Lloyd, 2005), young people face both new challenges and new opportunities created by cultural and economic globalization. In order to fully understand the situation of young people in developing countries today it is important to understand the rapid demographic changes that produced the historically unprecedented numbers of young people in the world today. These demographic changes potentially have important implications on the labor market opportunities, access to public resources, and access to family resources for youth.

\section{Data and Definitions}

This paper uses the population estimates and projections provided by the United Nations Population Division in World Population Prospects: The 2004 Revision Population Database. Most of the analysis is based on the "medium variant" in the United Nations projections. A detailed description of the assumptions used for these projections is provided in Appendix A. In keeping with the definition adopted for the World Development Report 2007, the youth population is defined as the population aged 12-24. In some cases, such as the comparison of projections with and without HIV/AIDS, estimates are only available in five-year age groups. In these cases the population aged 10-24 is used to represent the youth population. The countries included in the analysis here include all of the countries classified as low-income to middleincome by the World Bank, plus a selected group of Eastern European countries. In some cases high-income countries are included for comparative purposes. 


\section{The Peak in Youth Population}

According to the population projections of the United Nations Population Division, the number of young people in the world is close to reaching its historical peak, a peak that will arguably be the largest number of young people the world will ever see. Figure 1 shows the number of 12-24 year-olds in the world and in three major developing regions - Asia, Africa, and Latin America - according to the U.N. medium variant projections. The population numbers have been normalized to an index where $1950=100$ for all regions in order to simplify comparisons across regions. Although projections as far out as 2050 must be viewed with caution, projections over the next two decades are relatively straightforward. The projections to 2050 are shown because they give a picture of at least one reasonable scenario for the trends that will be experienced in the coming decades. As suggested by Figure 1, there is little question that current youth cohorts are the largest that the world has ever seen, and that a period of rapid growth in the size of these cohorts is coming to an end. While the world population aged 12-24 more than doubled in the 35 years between 1950 and 1985, a historically unprecedented rate of growth, the world's youth population is projected to decline in the 35 years after 2010.

As shown in Figure 1, the pattern for the world as a whole reflects wide diversity across regions. With Asia accounting for almost two-thirds of the world population, the pattern for Asia is very similar to the pattern for the world as a whole. The rapid approach of the peak in the youth population is more clearly evident in Asia, however, with a projected peak around 2010. Latin America and the Caribbean are also approaching a peak, with a broad leveling off that begins around 2010. Figure 1 shows that the pattern for Africa is substantially different, however. The youth population in Africa, which is already more than four times its 1950 level, is 
projected to continue growing until beyond 2050, with the 2050 level being eight times the level of 1950.

\section{Classifying demographic patterns}

These trends in the size of the youth population are driven by complex changes in fertility, mortality, and population momentum that will be discussed in detail below. Because these underlying demographic trends have followed similar patterns in many countries, it is possible to characterize four major patterns describing trends in the size of the youth population. The criterion used to classify countries is the timing of the peak in the youth population. As illustrated by the example of Latin America in Figure 1, this peak is often not a sharp peak, but may be more characterized by a slow leveling off. For this reason the classification is based on both the year in which the population aged 12-24 reaches a peak and the rates of growth of the youth population around specific years. The definitions of the four specific categories are given in Table 1.

Table 1. Definition of categories of the timing of the peak in the size of the population aged 12-24

\begin{tabular}{|c|l|}
\hline Category & \multicolumn{1}{|c|}{ Definition } \\
\hline 1 & $\begin{array}{l}\text { Countries with peak in youth population before } 2000 \\
\text { Definition: countries in which the maximum youth population over the period 1950- } \\
\text { 2050 occurred prior to 2000 }\end{array}$ \\
\hline 2 & $\begin{array}{l}\text { Countries with peak between } 2000 \text { and } 2010 \text {. } \\
\text { Definition: countries in which the peak youth population occurs between } 2000 \text { and } \\
\text { 2010 OR the peak population occurs after } 2010 \text { but the growth rate between } 2005 \\
\text { and 2015 is below 0.5\% per year }\end{array}$ \\
\hline 3 & $\begin{array}{l}\text { Countries with peak between } 2010 \text { and } 2030 \\
\text { Definition: countries in which the peak youth population occurs between } 2010 \text { and } \\
\text { 2030 and the growth rate between 2005 and 2015 is above 0.5\% per year } \\
\text { OR the peak youth population occurs after 2030 but the growth rate between } 2025 \\
\text { and 2035 is below 0.5\% per year }\end{array}$ \\
\hline 4 & $\begin{array}{l}\text { Countries with peak after } 2030 \\
\text { Definition: countries with peak after } 2030 \text { and with growth rates above 0.5\% per year } \\
\text { between 2025 and 2035. }\end{array}$ \\
\hline
\end{tabular}


Table 2 shows the distribution of the 154 countries included in our analysis into these four classifications. While the largest number of countries fall in Group 4, it is important to keep in mind that this does not necessarily represent a larger population than the other groups. Countries with large populations in Group 2 include Indonesia, Brazil, Mexico, and Vietnam, the third, fourth, eighth and ninth largest developing countries, respectively, in 2005. Group 3 includes India, Bangladesh, and the Philippines, the second, sixth, and tenth largest developing countries. Group 4 includes Pakistan and Nigeria, the fifth and seventh largest developing countries. With China in Group 1, the population of developing countries is spread quite broadly across the four classifications.

Table 2. Classification of countries by timing of peak in the population aged 12-24

\begin{tabular}{|l|c|c|}
\hline \multicolumn{1}{|c|}{ Category } & Frequency & Percent \\
\hline 1. Peak before 2000 & 31 & 20.1 \\
\hline 2. Peak between 2000 and 2010 & 37 & 24.0 \\
\hline 3. Peak between 2010 and 2030 & 31 & 20.1 \\
\hline 4. Peak after 2030 & 55 & 35.7 \\
\hline Total & 154 & 100 \\
\hline
\end{tabular}

Appendix B provides a complete classification of 154 countries. Appendix C presents figures showing the population aged 12-24 between 1950 and 2030 for each of these countries. As would be expected from Figure 1, Asian and Latin American countries are mostly found in Groups 1 and 2, while African countries dominate Groups 3 and 4.

Figures 2-5 show selected countries in each of the four groups. Figure 2 shows the two major developing countries in Group 1, China and Thailand, countries, which had already reached a peak in the size of the youth population before 2000. Both countries had rapid fertility declines in the 1970s and 1980s, with Total Fertility Rates that were close to the replacement 
fertility level of 2.1 by the 1990s. The peak of the youth population was about 2.8 times its 1950 level in Thailand, about 2.4 times its 1950 level in China.

Figure 3 shows a group of countries in the second group, with a peak in the youth population occurring roughly between 2000 and 2010 - Brazil, Costa Rica, Indonesia, Mexico, and Vietnam. The magnitude of the peak, measured relative to the 1950 youth population, varies considerably. Indonesia's youth population will peak at around 2.5 times its 1950 level, Costa Rica's youth population will reach over 5 times its 1950 level, with the other countries in between. Note that the peak is not very pronounced in any of these countries, with more of a long leveling off than a sharp peak. Most of these countries are projected to have relatively constant youth populations for several decades.

Figure 4 shows a group of countries that will reach a peak in their youth populations between 2010 and 2030 - India, Egypt, Malaysia, Peru and the Philippines. These are countries that have had later fertility declines than the group of countries shown in Figures 2 and 3. As in Figure 2, most of these countries are projected to experience 20 or 30 years of relatively constant youth populations after they reach their peak.

Figure 5 shows a group of countries that still have rising youth populations in 2030 - the Democratic Republic of Congo, Iraq, Kenya, Pakistan, and Senegal. As the figure demonstrates, there is considerable heterogeneity within this group. Some countries with very late fertility declines, such as Kenya and the Democratic Republic of Congo, are projected to have continued rapid growth of the youth population for the next several decades. Other countries, such as Pakistan and Senegal, are projected to have slower growth, leveling off shortly after 2030. 


\section{The Impact of HIV/AIDS}

For some countries, especially countries in southern Africa, assumptions about AIDS mortality can have a significant impact on the projected size of the youth population. The population projections of the U.N. Population Division include projections about AIDS mortality and about the potential impact of anti-retroviral treatment. The population projections incorporate the UNAIDS model that is used to project the course of the epidemic in the 60 countries with high HIV prevalence (UNAIDS Reference Group on Estimates, Modelling and Projections, 2002). The complete set of projections also includes an alternative projection in which it is assumed that there is no AIDS mortality. These alternative "No HIV/AIDS" projections are made for the 60 countries with high HIV prevalence, with projections made from 1980 to 2050. Figure 6 shows the medium variant projection, which includes AIDS mortality, and the alternative “No AIDS” projection for three countries with high HIV prevalence Botswana, South Africa, and Zambia. These projections use the 10-24 age group, rather than the 12-24 age group, since single year of age estimates are not available for the "no AIDS" projections.

Figure 6 demonstrates that AIDS mortality has a substantial impact on the size of the youth population in these southern African countries. There is little difference in the two projections in 2000, but by 2010 the projections begin to diverge. In Botswana, for example, the youth population is projected to peak around 2005 by the medium variant projection, but under the alternative “No AIDS” projection it would have continued increasing for several more decades. The medium variant youth population in 2015 in Zambia is projected to be about 15\% lower than it would have been in the absence of HIV/AIDS. 


\section{Why current youth cohorts are so large}

It is useful to consider the demographic explanations for the large size of current youth cohorts, and the explanations of why many countries are close to their peak youth population. The explanations for these trends are important for a number of reasons. In addition to helping understand the sources of the current "youth bulge,” an understanding of the underlying processes helps put this bulge in perspective. It also helps us understand some important features of today's youth cohorts, such as the paradoxical fact that they were born into much smaller families than those of their parents.

\section{Key Features of the Demographic Transition}

Demographers use the term “demographic transition” to refer to the pattern of changes in fertility, mortality, and population growth that have been observed with a high degree of regularity around the world. The stylized description of the demographic transition starts with a regime in which both death rates and birth rates are relatively high and roughly equal, implying low rates of population growth. The demographic transition begins with a decline in death rates, potentially driven by a variety of factors. With death rates falling, birth rates typically remain high for some period of time, generating population growth. Eventually birth rates also fall, slowing the rate of population growth. The transition ends when birth rates and death rates have both stabilized at a new low level, implying a return to low (or zero) population growth. The pace at which mortality and fertility decline and the length of time between mortality decline and fertility decline determine the rate of population growth that will be observed during the demographic transition.

High-income countries, which went through the demographic transition in the 1800s or early 1900s, typically experienced long and relatively slow mortality decline. The gap between birth 
rates and death rates was never very large, and population growth rates rarely exceed $1 \%$ per year. The demographic transition that took place in developing countries was quantitatively quite different. Death rates declined very fast, generating population growth rates that exceeded $4 \%$ per year in some countries (implying doubling times of less than 20 years).

It is instructive to look at the history of the demographic transition for a specific country. This section will look at the case of Brazil, a country whose mortality decline and fertility decline were fairly typical of countries that have now progressed quite far through the demographic transition. Brazil has exceptionally good data with which to track demographic changes at both the macro and micro level, including detailed census data back to 1960 . Figure 7 shows the brod overview of the demographic transition in Brazil, based on the United Nations estimates of birth rates, death rates and population growth rates from 1950-55 to 2000-05. ${ }^{1}$ The figure shows that the demographic transition was already well underway in Brazil by 1950, with the crude death rate having fallen to 15 per 1000, while the crude birth rate was almost 45 per 1000 . The rate of population growth was about 28 per 1000, or $2.8 \%$ per year, in the 1950s, a rate much higher than was ever experienced by currently high income countries when they went through the demographic transition. Although the crude birth rate was falling in the 1950s, death rates were falling faster, causing a peak population growth rate of 3.0\% in the 1960-65 period. This was also the period in which world population growth rates reached their historic peak, at around 2\% per year (Lam, 2005).

\footnotetext{
${ }^{1}$ The crude birth rate is defined as the number of births per year divided by the total mid-year population, expressed as a ratio of births per 1000 population. The crude death rate is deaths per year per 1000 population. The rate of natural increase is simply the difference between the crude birth rate and the crude death rate. The rates shown are estimates of the average annual rates in each five-year period.
} 
It is important to look back at the rapid population growth of the 1960s, because this is in many ways the origin of today's large youth cohorts. If we consider the children born in developing countries in the 1960s to be the children of the population explosion, today's youth cohorts are the grandchildren of the population explosion, the children of those earlier large cohorts. It is important to keep in mind this fundamental aspect of today's youth cohorts.

While the crude birth rates and crude death rates in Figure 7 are the ultimate determinants of the population growth rate, they are not the best indicators of fertility behavior of basic mortality conditions. Because they are simply ratios of the numbers of births and deaths to the total population, they can be very sensitive to the age structure of the population. Figure 8 shows the Total Fertility Rate (TFR) and Infant Mortality Rate in Brazil over the 1950-2005 period. The TFR is the sum of age-specific fertility rates in a given year, and can be interpreted as the number of births a woman would have in her lifetime, given the age-specific probabilities of birth in that year. Unlike the crude birth rate, which is affected by the population age structure, the TFR is a useful summary of the actual fertility behavior of women in a given period. The crude death rate is also highly affected by the population age structure, and is thus a very imperfect measure of the actual mortality situation in a given period. The infant mortality rate, which measures the number of births that die before age 1 divided by the total number of births (expressed per 1000 births), is much better than the crude death rate at showing the decline in mortality. It was declines in infant mortality that played the most important role in driving declines in the overall death rate during the demographic transition. As shown in Figure 8, infant mortality was falling rapidly in Brazil in the 1950s, but fertility did not begin to fall until the 1960s. These patterns for Brazil are very typical of patterns in fertility and mortality throughout the developing world between 1950 and 2000. While the timing and pace of the decline varies across regions, virtually 
all developing countries experienced rapid mortality decline, a period of high population growth, and eventually fertility decline.

The size of surviving birth cohorts during the demographic transition was influenced by a complex interaction of fertility, mortality, and population momentum. Population momentum refers to the inertia that is inherent in population dynamics due to the fact that childbearing takes place two to three decades after birth. The rapid growth of birth cohorts in the 1950s and 1960s produced a rapid growth of the childbearing-age population in the 1970s, 1980s, and beyond. This growth of the childbearing-age population competed with the decline in fertility rates to determine the size of birth cohorts.

A good picture of trends in cohort size is provided by looking again at the case of Brazil, where excellent census data back to 1960 provides an unusually detailed record. Figure 9 shows the size of cohorts as they appear in the censuses from 1960 to 2000, using only the age groups below the age of 20 in each census. These are not the size of the birth cohorts at the time they were born, but rather are the size of the birth cohort as it had survived to the census. It is thus a fairly good measure of the size of surviving birth cohorts, a useful measure if we are interested in the size of youth cohorts. The figure shows that birth cohorts grew rapidly in the 1950s and 1960s, leveled off in the late 1960s and early 1970s, then grew rapidly again in the late 1970s, reaching a peak in 1982. These trends in cohort size provide a convenient summary of the population dynamics of the demographic transition. The rapid growth in the size of surviving birth cohorts during the 1950s and early 1960s reflected the rapid decline of infant and child mortality. The leveling off in the late 1960s reflected the rapid decline in fertility rates that began in the 1960s in Brazil. The rapid growth in the size of cohorts born in the late 1970s was due to population momentum, resulting from the increase in the size of the childbearing 
population as the birth cohorts of the 1950s reached childbearing age. The largest birth cohort in Brazil was born in 1982, the point at which falling fertility finally overtook population momentum. The experience for other countries will have been similar to that for Brazil, with differences only in the specific timing of the largest cohort.

\section{Trends in Growth Rates and Relative Cohort Size}

While there are many reasons to take note of the unprecedented size of current youth cohorts, for many economic issues it may be the growth rate of the youth population, or its size relative to other age groups, that is the critical variable. As suggested in Figures 1-5, the growth rates of youth populations in most countries are lower today than they were in previous decades. Indeed, it is virtually a mathematical necessity that the growth rates must be declining if the total size of the youth population is near its peak, given the smoothness inherent in most population dynamics. Figure 10 shows the annual growth rate of the youth population in the same set of countries shown in Figures 2-5 above (note that the vertical scales differ across panels). The growth rate shown is the average annual rate of growth between two of the five-year population totals shown in Figures 2-5 (for example, the first point in each graph is placed at 1952.5, and represents the average annual growth rate between 1950 and 1955). Looking across all four panels of Figure 10, several important features can be seen. Most importantly, the peak in the growth rate of the youth population occurs around the 1965-70 period in almost all of the countries, especially for countries in the first three classifications.

It is interesting to compare, for example, Thailand in Panel A and the Philippines in Panel C. Thailand, which experienced its largest youth population around 1990, had its highest rate of growth of the youth population in 1965-70, a growth rate of about 4\%. The youth population in the Philippines is projected to continue growing until around 2020, with a growth rate in the 
2000-2010 period of about $1.5 \%$ per year. But the peak growth rate of the youth population in the Philippines also occurred in the $1965-70$ period, with a growth rate of $3.7 \%$. It is noteworthy how many countries shown in Figure 10 had relatively similar experiences, reaching a peak growth rate of the youth population around 1970 of about 3-4\% per year. The major differences across countries in the first three panels of Figure 10 are less in the timing and magnitude of the peak growth rate than in the speed at which the growth rate declined in the 1980s and 1990s. This reflects the fact that most developing countries experienced similar levels of rapid population growth in the 1960s. The subsequent rate of decline in fertility rates differed substantially across countries, however, and it these differences that drive the differences in the rate of decline in the growth rate of the youth population during the 1980s and 1990s.

For some economic and social questions it may be the percentage of the population in youth age groups that is most important. Figure 11 shows the percentage of the total population that is aged 12-24, continuing to use the same countries and population projections used thus far. An important lesson of Figure 11 is that most countries have already experienced the peak in the percentage of the population that is aged $12-24$. This peak occurs at around $25-30 \%$ of the population in most countries.

While the youth population as a percentage of the total population may be important for some purposes, a more important indicator may be the size of the youth population relative to the working age population. As will be discussed below, two important strands of literature in economic demography have focused on relative cohort size - the literature on the impact of cohort size on the youth labor market, and the literature on the "window of opportunity" resulting from a favorable ratio of the working age population to the dependent population. Figure 12 shows the ratio of the population aged 12-24 to the population aged 25-59. Once again we see 
that the period of the most dramatic relative numbers of youth were experienced several decades ago in most countries. Most countries in the first three panels of Figure 12 experienced the largest peak of the youth population relative to the working age population in the 1970s or 1980s. As was the case with the growth rate of the youth population, in many cases we see similar patterns in the timing and magnitude of the peak in the relative size of youth cohorts for countries that look quite different in terms of the timing of the peak in the total size of the youth population. Thailand and the Philippines both reached a peak around 1975, when there were about 0.9 12-24 year-olds for every 25-59 year-old. The difference in the countries is that this ratio had fallen to about 0.5 in Thailand in 2005, while in the Philippines it was still over 0.7.

Even in the countries in Panel D, where the youth population will continue to grow for the next several decades, the ratio of the youth population to the working-age population has in most cases already begun to decline. To the extent that this ratio is a critical measure of the pressure the youth population places on resources or labor markets, it is important to recognize that the pressure has already begun to diminish in most countries.

\section{Family Size versus Cohort Size}

One of the important, if somewhat paradoxical, features of population dynamics during the demographic transition is that the size of birth cohorts can move in the opposite direction from the size of families. This is another consequence of population momentum, which can cause a gap in the timing between the decline in fertility and the decline in the size of birth cohorts. Lam and Marteleto (2005) analyze the case of Brazil, using the detailed census and survey data back to 1960 . As can be seen by comparing Figure 8 and Figure 9 above, there is roughly a fifteen year delay in Brazil between the onset of fertility decline, which occurs in the late 1960s, and the birth of the largest birth cohort in 1982. This means that there is a period in which family size is 
on the decrease while cohort size is on the increase, potentially creating offsetting effects in terms of resources available to children and youth.

Using the micro data from the Brazilian censuses of 1960, 1970, 1980, 1991, and 2000, Lam and Marteleto analyze the number of siblings born to different cohorts of young people. These estimates are made by matching young people to their mothers in the census and using the mothers' reports of children ever born and children surviving. Figure 13 shows the average number of siblings ever born and siblings still surviving at the time of the census for youth aged 12-14 in each of these Brazilian censuses. Note that the surviving number of siblings increases slightly between 1960 and 1970, even though the number of siblings ever born declines. This represents the effect of rapidly falling infant and child mortality, which more than offset the decline in fertility that had already begun to appear. Between the 1970 and 1980 censuses the impact of falling fertility more than offset the impact of declines in infant and child mortality, with young people in 1980 having fewer surviving siblings than their counterparts in 1970. The number of surviving siblings fell by almost one child between the 1980 and 1991 censuses and again between the 1991 and 2000 censuses. The cumulative decline between 1960 and 2000 was 2.3 siblings, a 44\% decline. As shown by Lam and Marteleto, this decline was driven in particular by a decline in the prevalence of large families. The result was a significant decline in the competition for resources within families, potentially an important factor affecting their health and schooling. At the same time, most of these young people were being born at a time when cohort size was rapidly increasing, implying increased competition for resources at the macro level. The pattern observed in Brazil is similar to that in most developing countries. Many of today's young people grew up in a period in which cohort size was increasing but family size was decreasing, implying that they have had to compete with rising numbers of 
children from other families in getting access to school or health care, at the same time that they have had to compete with fewer siblings in their own families.

\section{Comparisons to Youth Demography in High-income Countries}

Before discussing the economic implications of trends in youth demography in low-income and middle-income countries, it is interesting to compare these trends to those observed in recent decades in high-income countries. A large literature focused on the impact on the labor market of the baby boom cohort in the United States and a related "youth bulge” in Europe. How did the changes in the relative size of the youth population in the United Sates and Europe compare to the changes that have been taking place in developing regions?

Figure 14 shows the growth rate of the youth population and the ratio of the youth population to the working-age population for the France, Netherlands, United Kingdom, and United States, countries in which there has considerable focus on the implications of youth cohort size in recent decades. Looking at the annual growth rates in Panel A, it is interesting to note that growth rates approaching $4 \%$ per year were seen in several countries. These are similar to the peak growth rates of the youth population observed in most developing countries, as shown in Figure 10. The cause of these spikes in the youth population was very different in the highincome countries than it was in the developing countries. The fluctuations in age structure in the high-income countries were driven by sudden increases in the birth rate in the 1950s. These baby booms were followed by equally rapid declines in birth rates, generating large swings in the size of cohorts born over these decades.

Looking at the ratio of the youth population to the working-age population in Panel B, these levels also exhibit a range of variation over short periods of time that is similar to the range experienced in developing countries. The absolute level of this ratio remains at levels well below 
those observed in developing countries during the 1970s and 1980s, however. In the United States the ratio of the youth population to the working-age population fell by $38 \%$ between the 1975 and 2000, from 0.6 to 0.37 . Thailand and Brazil also had a peak in this ratio in 1975, with declines between 1975 and 2000 of 44\% in Thailand and 27\% in Brazil. An important difference is that Thailand and Brazil, like most of the other countries shown in Figure 12, had continued declines in the relative size of the youth population after 2000, while the United States and Europe have had a relatively constant ratio of the youth population to the working-age population.

\section{Economic Implications of Youth Demography}

The demographic patterns documented above have potentially important economic implications. The following sections discuss specific areas in which youth demography may make a significant economic impact, with particular focus on labor markets, savings, and public expenditures.

\section{Youth Labor Markets}

One of the most obvious areas in which to consider the economic implications of changes in the absolute and relative numbers of young people is in the youth labor market. Economic theory predicts that the absolute size, relative size, and rate of growth of the youth population could all potentially have an impact on the wages and employment opportunities of young people. Which of these variables will have the largest impact will depend on the nature of the labor market, the degree of complementarity or substitutability of youth labor with other factors of production, and the speed of adjustment of other factors in response to changes in the supply of youth in the labor market. The absolute size of the youth population will be important in relationship to the total quantity of other factors of production. Some of these factors, such as land, may in fact be 
relatively fixed in supply, though in practice the supply of land has been a relatively unimportant component in explaining economic growth, wage levels, or levels of poverty even during the last fifty years of rapid population growth (Johnson, 2000, Lam, 2005).

Physical capital is the most important non-labor factor or production. While it is beyond the scope of this paper to discuss the determinants of capital accumulation, there is little reason to think that the capital stock is independent of the absolute size or rate of growth of the labor force. This implies that the absolute size of the youth population is unlikely to have any particular economic significance in and of itself, especially in terms of the labor market. A high rate of growth of the youth population, however, may be of more economic interest, since it may push against the rate of growth of physical capital, potentially leading to lower wages or at least lower wage growth. This will be discussed below in regard to the impact of cohort size on savings. To the extent that it is the growth rate of the youth labor market that has important economic implications, it is important to recall from Figure 10 that the rate of growth of the youth population has been declining in most developing countries for several decades. While a number of countries, especially in Africa and south Asia, continue to have growth rates of their youth population of around $2 \%$ per year, a rate that can add significantly to the employment challenges facing these countries, these growth rates are comfortably below the $3 \%$ or $4 \%$ growth rates that were experienced by most developing countries in the 1970s, and the growth rates are steadily declining.

In addition to land and physical capital, youth labor gets combined with the labor of more experienced workers. The relationship between youth workers and older workers may be one of the most important economic aspects of youth cohort size, and has been the focus of attention in several strands of literature. As mentioned above, there is a large literature in labor economics 
and economic demography analyzing the impact of cohort size on the labor market in the United States and Europe. Research on the United States, such as Freeman (1979), Welch (1979), and Berger (1985, 1989), looked at the initial earnings and subsequent earning growth of the large baby boom cohort that entered the labor market in the 1970s. Many European countries also experienced declining fertility in the 1960s that resulted in declines in the size of youth cohorts entering the labor market in the 1980s. Korenman and Neumark (2000) provide a useful review of the research that analyzing the impact of cohort size on labor markets in Europe.

A broad consensus from the research on the labor market impact of relative cohort size in the United States and Europe is that there does appear to be a negative impact of relative youth cohort size on the wages and employment opportunities of young people. Most of these studies use some measure of the relative number of young workers to older workers, similar to the relative cohort size used in Figure 12. Most studies that examine the longer term experience of cohorts find that the negative impact of being in a large youth cohort tends to diminish over time. In some studies, the disadvantage of being in a large cohort almost completely disappears as the cohort ages. Other studies find more persistent effects. Using cross-national data from OECD countries from 1970 to 1994, Korenman and Neumark estimate an elasticity of youth unemployment to relative cohort size of around 0.5. They conclude that the impact of relative cohort size is easily swamped by other macroeconomic and labor market conditions, and argue that cohort size per se is unlikely to have a major impact on unemployment rates in OECD countries.

While it is potentially misleading to apply the results of this research on OECD countries to developing countries, several points are worth noting. First, as shown in the figures above, the fluctuations in relative cohort size in OECD countries are roughly similar in magnitude to the 
changes experienced by developing countries. It is therefore perhaps reasonable to draw inferences based on the OECD experience, with the literature suggesting that larger relative cohort size will have a negative but relatively modest impact on youth employment prospects. A second point is that the relative size of youth cohorts, the measure that is the focus of study in most of this research, peaked in the 1970s and 1980s in many developing countries, and is beginning to decline even in the countries with the latest fertility decline. Combining the empirical evidence on the impact of cohort size with the demographic patterns, there would seem to be little reason to expect that developing countries will be experiencing a youth labor market crisis in the coming decades, at least as far as demographic pressure alone is concerned. On the contrary, the period of most rapid pressure on youth wages and employment has already been passed in most countries.

\section{Relative Cohort Size, Savings, and Public Expenditures}

Another important area in which there has been attention to the economic implications of relative cohort size is the literature on dependency burden and savings rates. This literature has a long history, going back to the work of Coale and Hoover (1958) and Leff (1969), who argued that countries with high population growth rates suffered from low savings rates due to the high ratio of children and youth to the working-age population. These arguments have taken on a somewhat different form in a body of work that focuses on the rapid changes in dependency burdens that take place during the demographic transition. Bloom and Williamson (1998) argue that a rapid rise in the ratio of the working population to the non-working population in East Asia between 1965 and 1990 played an important role in driving the East Asian "economic miracle." Bloom and Williamson argue that part of the effect of having faster growth in the working-age population is due simply to the faster growth of the labor force, increasing per capita output due 
to a concentration of the population in productive ages. In addition to this, however, they argue that there is an effect that works through savings and capital accumulation. This effect, which recalls the arguments of Coale and Hoover, involves a negative impact of the dependency rate on savings. The impact of dependency rates on aggregate savings derives in part from life cycle savings patterns, with older adults saving more than young adults.

The idea that countries experience a "demographic dividend” or “demographic bonus” when the working age population begins to grow faster than the pre-working-age population has been pursued in papers such as Bloom, Canning, and Malaney (2000) and Bloom and Canning (2001). While work such as Deaton and Paxson (1997) find limited support in micro-level data for the hypothesized link between age structure, savings, and economic growth, the idea of a demographic bonus has intuitive appeal in a number of dimensions. Some of these effects may be particularly relevant for youth. As pointed out by Lee (1994), public expenditures, especially when they are funded by taxes on income or consumption (as opposed to, say, mineral wealth) will be affected by the ratio of the taxpaying population to the beneficiary population. Youth will typically be net beneficiaries rather than net taxpayers, depending on the state to finance primary and secondary schooling, post-secondary education, training programs, and health programs. The relevant demographic variable will be the ratio of the youth population to the working-age population, although the growth rate of the youth population may also play a role to the extent that public expenditures are slow to respond to changing demand (as in the case of schools, for example, where physical facilities and the training of teachers will create inertia, even aside from funding issues).

As emphasized above, although the youth population is the largest it has ever been in most developing countries, the size of the youth population relative to the working-age population is 
lower in most countries than it was 20 years ago. The declines in this ratio have been considerable, with declines of $25 \%$ to $50 \%$ in many countries between their historic peak and the levels observed in 2005. Taken literally, a 25\% decline in this ratio, a decline that is quite common across developing countries, implies that a given dollar collected in taxes for secondary schooling from each working-age person could pay for a 33\% increase in school pending per youth in 2005, compared to the year of the peak ratio. These ratios are on the decline in almost every developing country, implying that from this perspective the economic circumstances for investing in youth are steadily improving.

\section{Conclusions}

This paper has documented the demography of youth in developing countries. Using the medium variant projections of the United Nations Population Division, it is clear that the youth population - the population aged 12-24 - in most developing countries is the largest it has ever been. In a number of countries the youth population is the largest it will be for many decades, and plausibly the largest it will ever be. Four broad patterns describe the timing of the peak in the youth population. A few countries, notably Thailand and China, already experienced the peak in their youth population before 2000, and are on a clear downward trajectory. A large second group, including numerous Latin American countries and East Asian countries, is experiencing a peak between 2000 and 2010. A third group, characterized by somewhat slower fertility decline than the countries in the first two groups, is projected to reach a peak youth population between 2010 and 2030. A fourth group of countries, including most of Africa as

well as some South Asian countries, is projected to continue with growth of its youth population until beyond 2030. These countries tend to be the poorest countries in the world, and have been late to experience declines in fertility. 
As illustrated with the specific case of Brazil, the explanation for today's large youth cohorts and for the timing of the peak in youth populations is directly linked to the rapid changes in mortality and fertility that produced the demographic transition. Today's youth cohorts are broadly speaking the children of the large cohorts born during the population explosion that peaked in the 1960s. Paradoxically, they were born during a period of rapidly falling fertility, with the large size of their cohorts driven by population momentum rather than high fertility. Because of this, today's youth were typically born into much smaller families were their parents. They have thus grown up with unusually heavy competition for resources due to large cohort size at the macro level, while competing with smaller numbers of siblings at the micro level.

The population dynamics of the demographic transition lead to a number of important features of today's youth demography. Although the absolute size of the cohorts is historically unprecedented, the growth rate of the youth population reached a peak in most developing countries around 1970. Growth rates of the youth population are well below the peak growth rates of the 1960s and 1970s, and continue to decline in most developing countries. This is true even in the group of poor countries the slowest fertility decline. Similar patterns are observed for the percentage of the population aged 12-24 and for the ratio of the youth population to the working-age population. The youth percentage reached a peak in many countries before 2000, although it will continue to rise in some of the countries that have the latest peak in the total youth population. The ratio of the youth population to the working-age population peaked considerably sooner than the youth percentage, having peaked in most countries in the 1970s or 1980s. This ratio is at or near its peak even in most of the countries with the highest fertility. There are potentially important economic implications from these trends in youth demography. The absolute size, the rate of growth, and the relative size of the youth population 
could all have an impact on economic growth rates, wages, unemployment, and public expenditures. Economic theory suggests that absolute size per se is probably the least important economic variable, however, since fixed factors of production are unlikely to be significant in these economies. The rate of growth of the youth population and the size of the youth population relative to other age groups are more likely to have important economic effects. A large literature on the impact of relative cohort size on labor markets in the United States and Europe suggests that large youth cohorts relative to the working-age population could have moderate negative effects on wages and employment. Research on the impact of age structure on economic growth in developing countries suggests that a large youth population relative to the working-age population can also have negative effects on savings and economic growth.

While this evidence suggests that large youth populations may have potentially negative economic effects, it is important that most developing countries have already experienced the peak in their youth population relative to the working-age population. This ratio has declined considerably since its peak in most countries, and will continue to decline in the coming decades. Countries that will have continued growth of the youth population beyond 2030 have the highest ratios of youth population to the working-age population, and many are just beginning to see the ratio decline. These countries face substantial challenges in providing youth employment and providing health and education services to these large youth cohorts. The ratio of youth to the working-age population is projected to decline in most of these countries over the coming decades, however, providing some relief as they try to meet the needs of their youth populations. 


\section{References}

Berger, Mark (1989) “Demographic Cycles, Cohort Size, and Earnings,” Demography 26(2):31121.

Berger, Mark C. (1985) “The Effect of Cohort Size on Earnings Growth: A Reexamination of the Evidence,” Journal of Political Economy, 93(3): 561-73

Birdsall, Nancy, Allen Kelley, and Steven Sinding (2001) Population Matters: Demographic Change, Economic Growth, and Poverty in the Developing World. Oxford University Press: New York.

Bloom, David, David Canning, and Pia Malaney (2000) "Population Dynamics and Economic Growth in Asia,” Population and Development Review, Supplement 2000; 26(0): 257-90

Bloom, David, and David Canning (2001) "Cumulative Causality, Economic Growth, and the Demographic Transition,” in Nancy Birdsall, Allen Kelley, and Steven Sinding, Editors, Population Matters: Demographic Change, Economic Growth, and Poverty in the Developing World. Oxford University Press: New York, 165-97.

Bloom, David, and Jeffrey Williamson (1998) “Demographic Transitions and Economic Miracles in Emerging Asia,” World Bank Economic Review 12(3): 419-55.

Coale, Ansley and Edgar Hoover (1958) Population Growth and Economic Development in LowIncome Countries, Princeton, N.J.: Princeton University Press.

Deaton, Angus, and Christina Paxson (1997) "The Effects of Economic and Population Growth on National Saving and Inequality.” Demography 34(1): 97-114.

Freeman, Richard B. (1979) "The Effect of Demographic Factors on Age Earnings Profiles,” Journal of Human Resources 14: 289-318.

Johnson, D. Gale (2000) “Population, Food, and Knowledge,” American Economic Review 90(1): $1-14$.

Korenman, Sanders, and David Neumark (2000) “Cohort Crowding and Youth Labor Markets: A Cross-National Analysis, in David Blanchflower and Richard Freeman, eds. Youth Employment and Joblessness in Advanced Countries. University of Chicago Press, Chicago: 57-105

Lam, David (1997) “Demographic Variables and Income Inequality,” in Mark R. Rosenzweig and Oded Stark, editors, Handbook of Population and Family Economics, Volume 1B, North-Holland - Elsevier Science, pp. 1015-1059.

Lam, David (2005) "How the World Survived the Population Bomb: An Economic Perspective," in Sisay Asefa, Editor, The Economics of Sustainable Development, W.E. Upjohn Institute for Employment Research, Kalamazoo, MI: pp. 99-132.

Lam, David, and Leticía Marteleto (2005) "Small Families and Large Cohorts: The Impact of the Demographic Transition on Schooling in Brazil," in Changing Transitions to Adulthood in Developing Countries, National Academy of Sciences, forthcoming. 
Lee, Ronald D. (1994) "Population Age Structure, Intergenerational Transfer, and Wealth: A New Approach, with Applications to the United States,” Journal of Human Resources 29(4): 1027-63.

Lee, Ronald, Andrew Mason, and Tim Miller (2000) "Life Cycle Saving and Demographic Transition: The Case of Taiwan,” Population and Development Review, Vol. 26 (Suppl.), 2000, pp. 194-222.

Leff, Nathaniel D. (1969) “Dependency Rates and Savings Rates,” American Economic Review, Vol. 59, 1969, pp. 886-896.

Lloyd, Cynthia (2005), Editor, Growing up Global: The Changing Transitions to Adulthood in Developing Countries, National Academies Press, Washington, D.C. .

Lutz, Wolfang, Warren Sanderson, and Sergei Scherbov (2001) “The End of World Population Growth,” Nature 412: 543-545.

Martine, George (1996) "Brazil's Fertility Decline, 1965-95: A Fresh Look at Key Factors,” Population and Development Review 22(1): 47-75, March.

Merrick, Thomas W. and Elza Berquó (1983) The Determinants of Brazil's Recent Rapid Decline in Fertility. Washington, DC: National Academy Press, Report No. 23.

National Research Council (2000) Beyond Six Billion: Forecasting the World's Population, Washington, D.C.

Potter, Joseph, Carl Schmertmann, and Suzanna Cavenaghi (2002) "Fertility and Development: Evidence from Brazil,” Demography 39(4): 739-761.

UNAIDS Reference Group on Estimates, Modelling and Projections (2002) "Improved methods and assumptions for estimation of the HIV/AIDS epidemic and its impact:

Recommendations of the UNAIDS Reference Group on Estimates, Modelling and Projections,” AIDS, vol. 16, pp. W1-W14.

United Nations Population Division (1999) The World at Six Billion, New York: United Nations.

United Nations, Department of Economic and Social Affairs, Population Division (2005). World Population Prospects: The 2004 Revision. CD-ROM Edition - Comprehensive Dataset (United Nations publications, Sales No. E.05.XIII.11).

United States Census Bureau (2003) “Historical Estimates of World Population,” retrieved from http://www.census.gov/ipc/www/worldhis.html.

Welch, Finis (1979) “Effects of Cohort Size on Earnings: The Baby Boom Babies’ Financial Bust, Journal of Political Economy. 87(5): S65-97.

Willis, Robert .J. (1973) “A new approach to the economic theory of fertility behavior,” Journal of Political Economy, March-April 1973, S14-S64.

World Bank (2001) World Development Indicators 2001, International Bank for Reconstruction and Development: Washington, D.C. 
Figure 1. Population Aged 12-24, World and Major Developing Regions (1950=100)

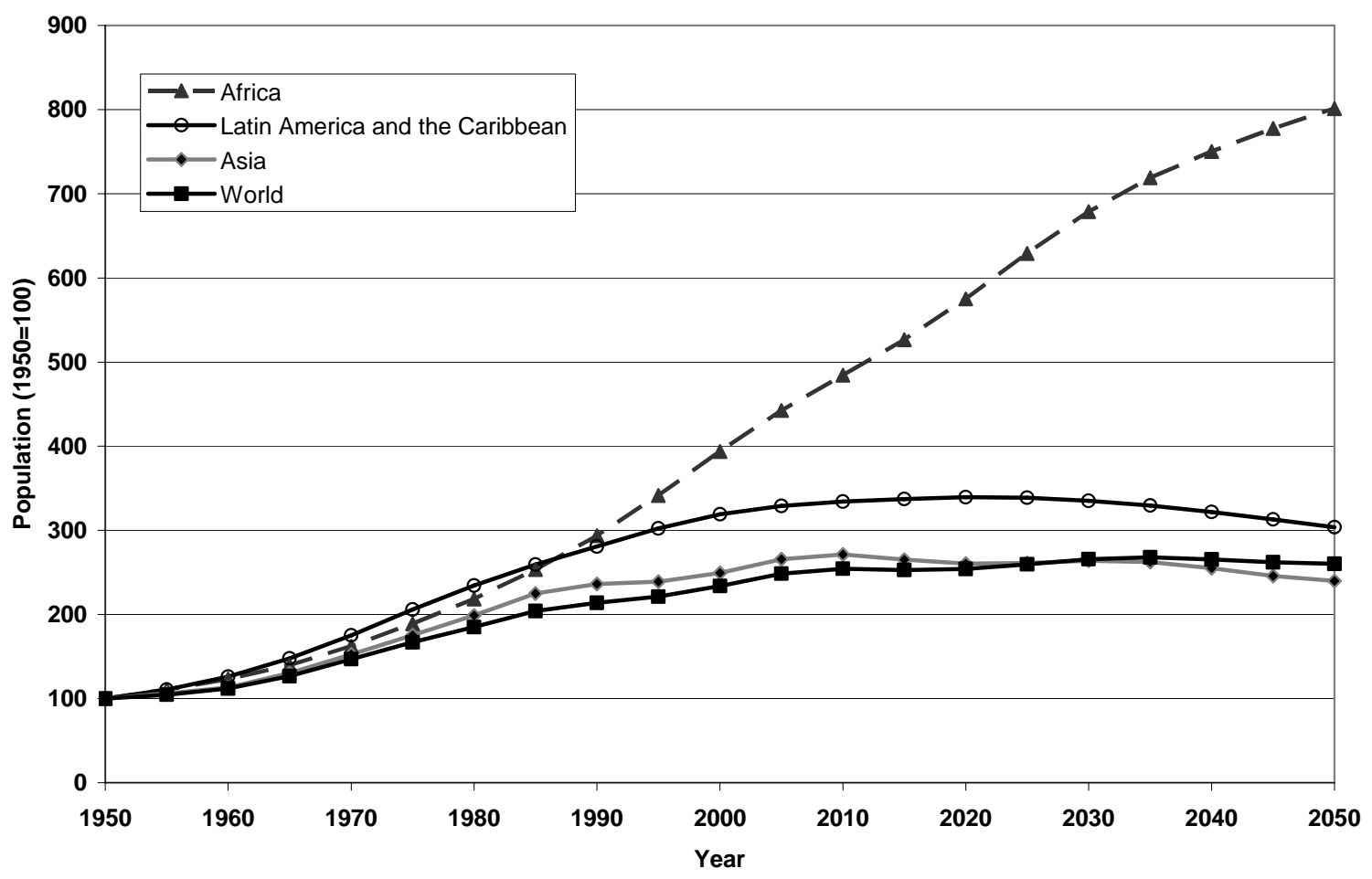


Figure 2. Selected Countries with Peak in Youth Population before 2000 Population Aged 12-24 (1950=100), U.N. Medium Variant Projections

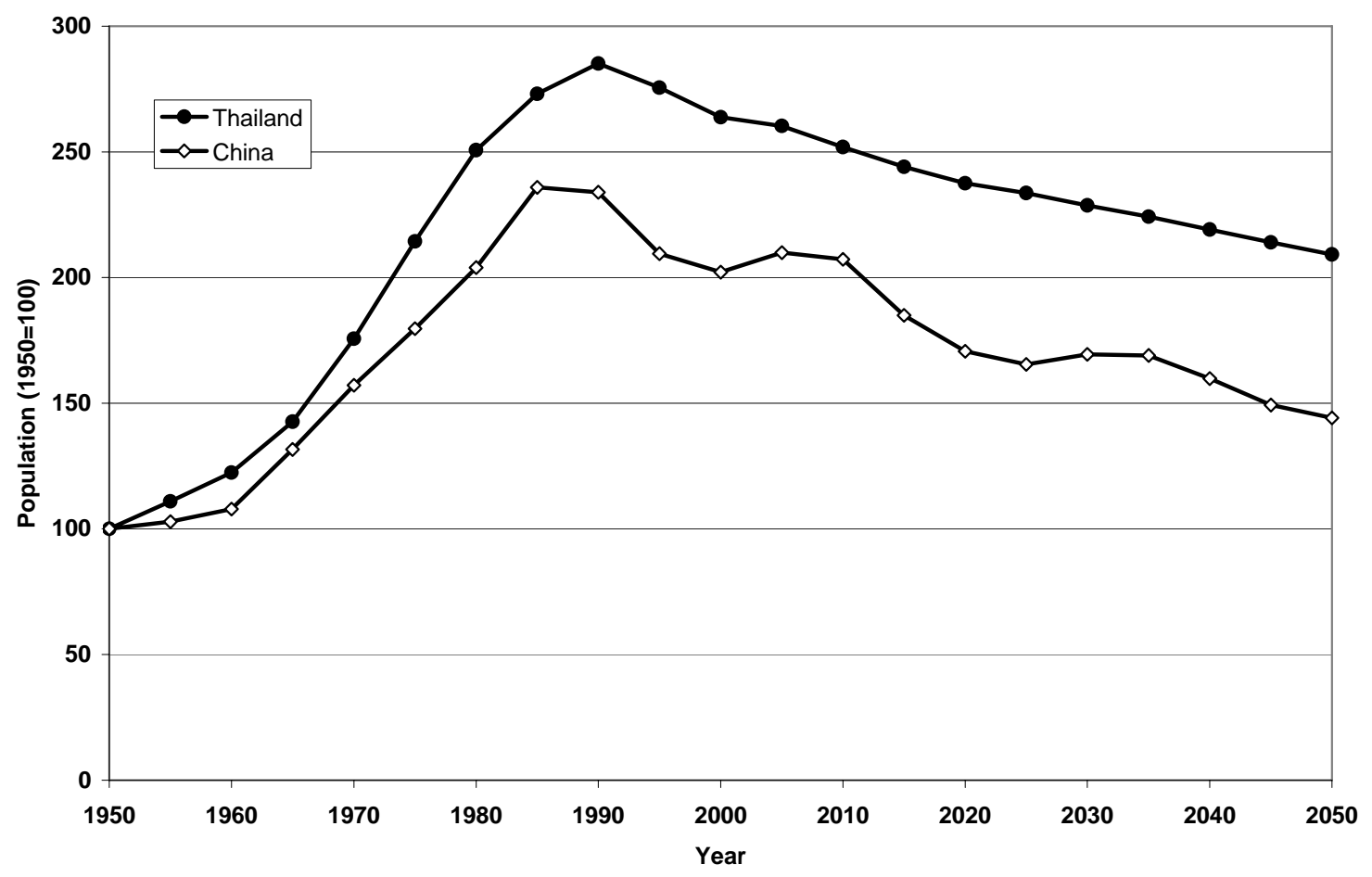


Figure 3. Selected Countries with Peak in Youth Population in 2000-2010

Population Aged 12-24 (1950=100), U.N. Medium Variant Projections

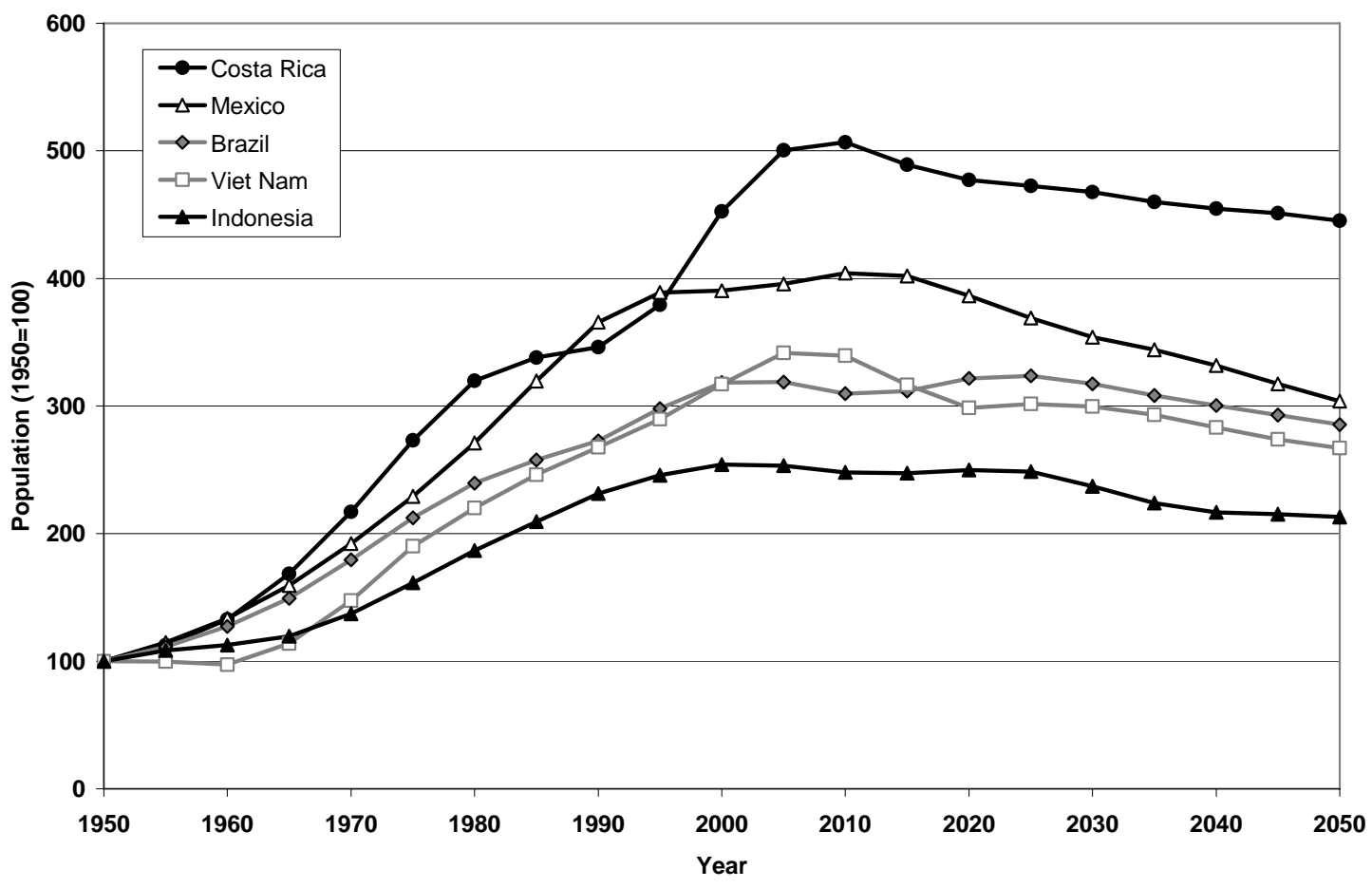


Figure 4. Selected Countries with Peak in Youth Population in 2010-2030

Population Aged 12-24 (1950=100), U.N. Medium Variant Projections

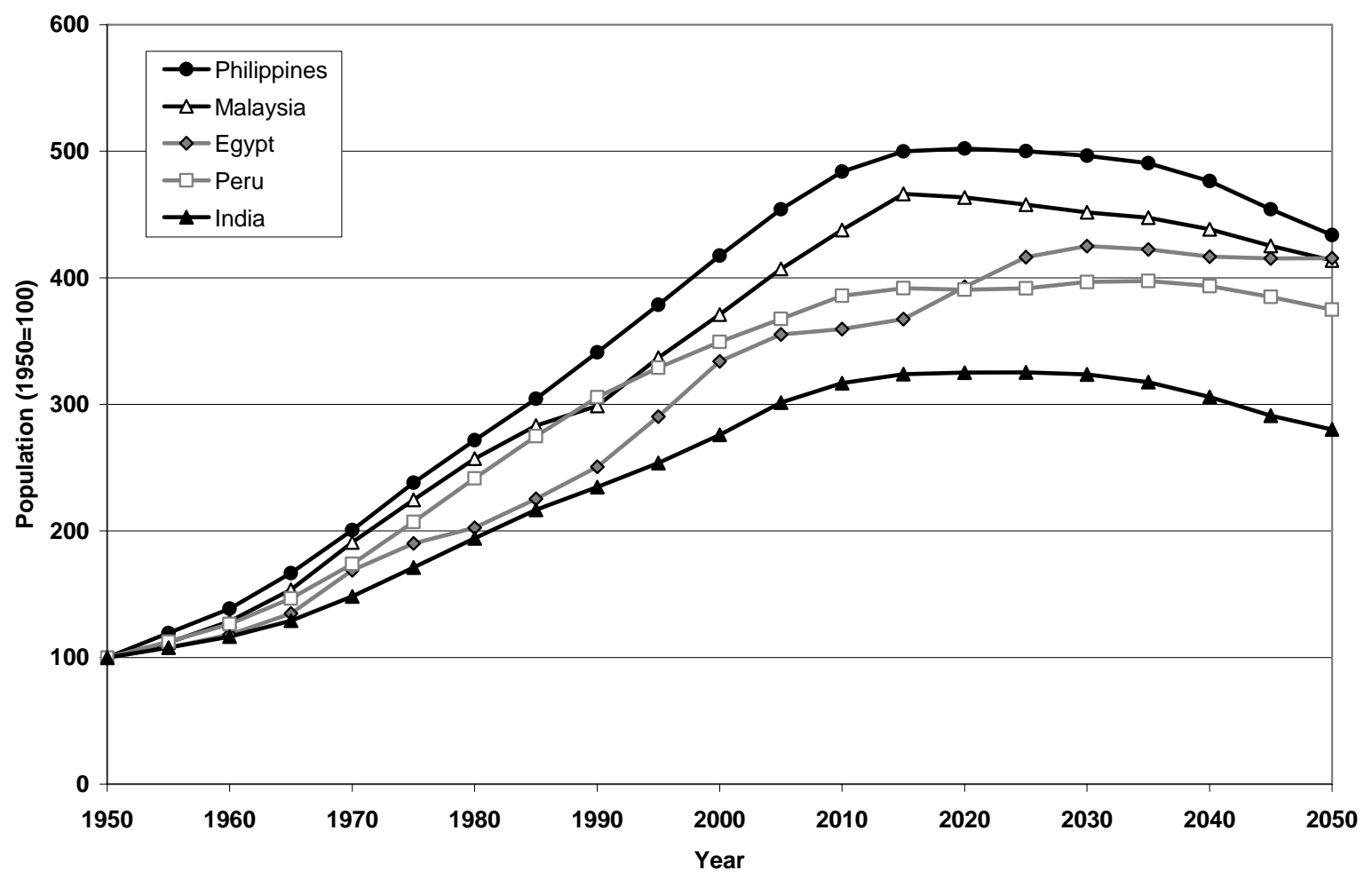


Figure 5. Selected Countries with Peak in Youth Population after 2030

Population Aged 12-24 (1950=100), U.N. Medium Variant Projections

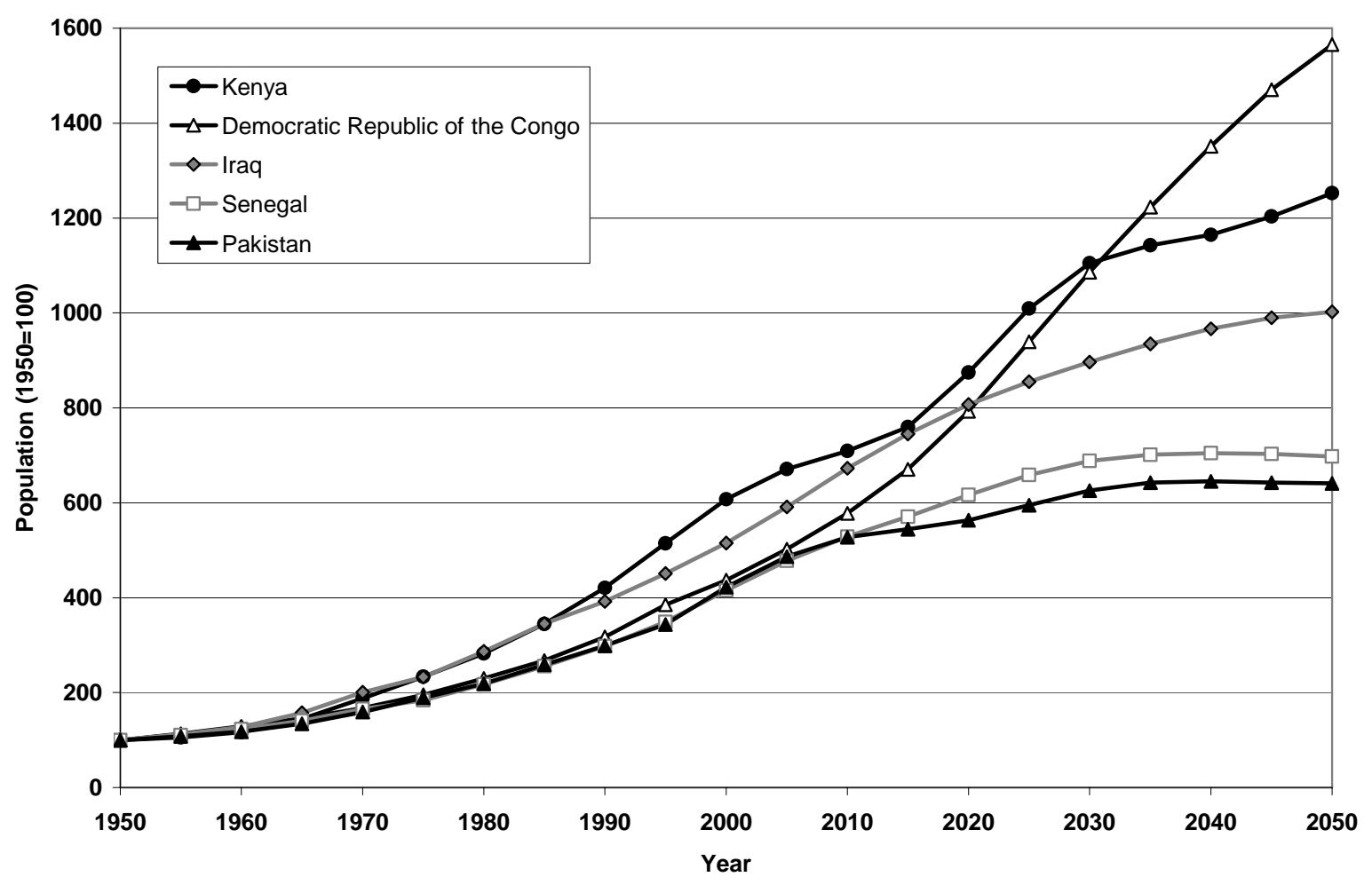


Figure 6. Projected Youth Population with and without AIDS

Population Aged 10-24 (1980=100), U.N. Medium Variant Projection and "No AIDS" Projection

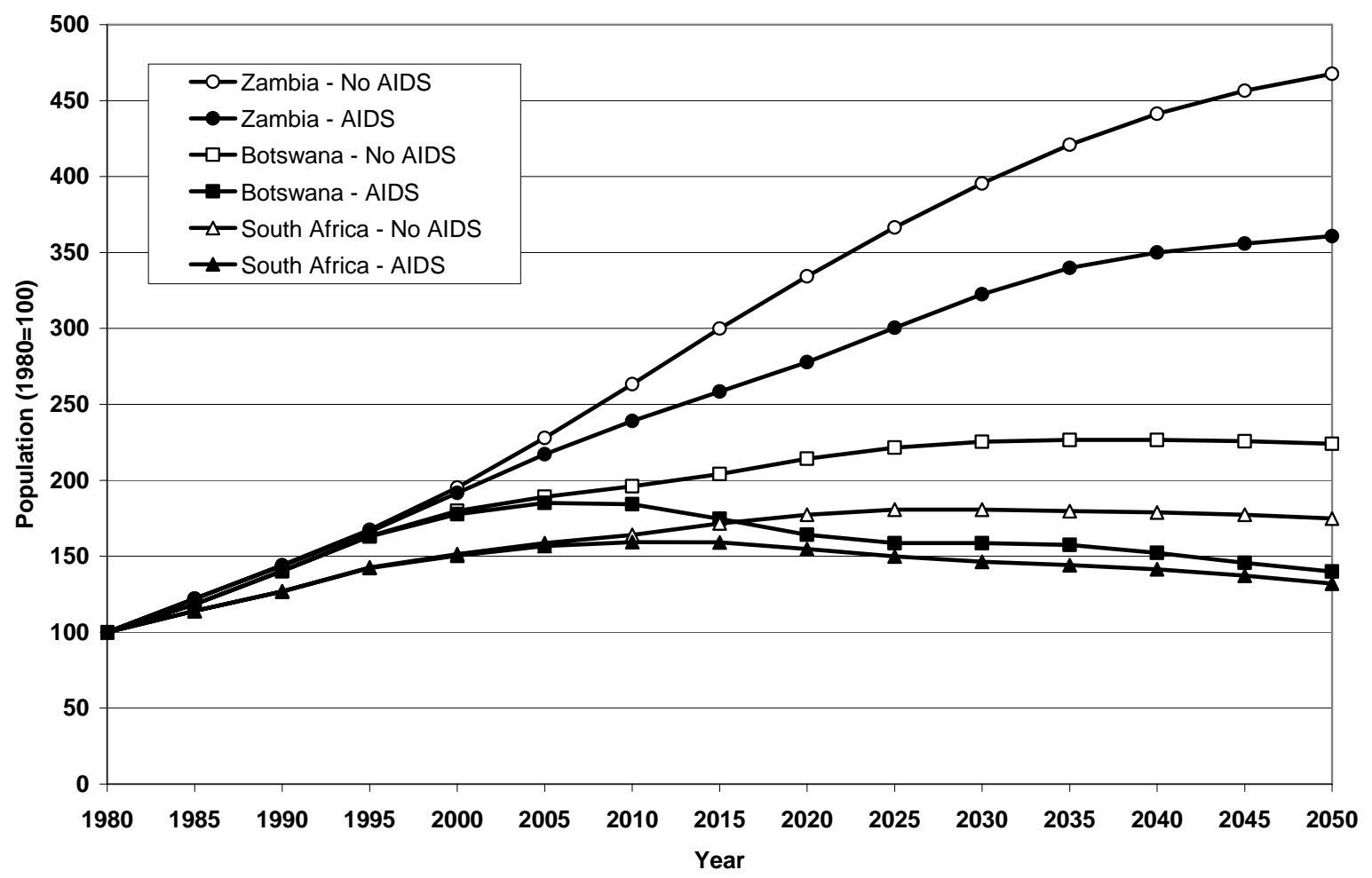


Figure 7. Demographic Transition in Brazil

Crude Birth Rate, Crude Death Rate, and Rate of Natural Increase, 1950-2005

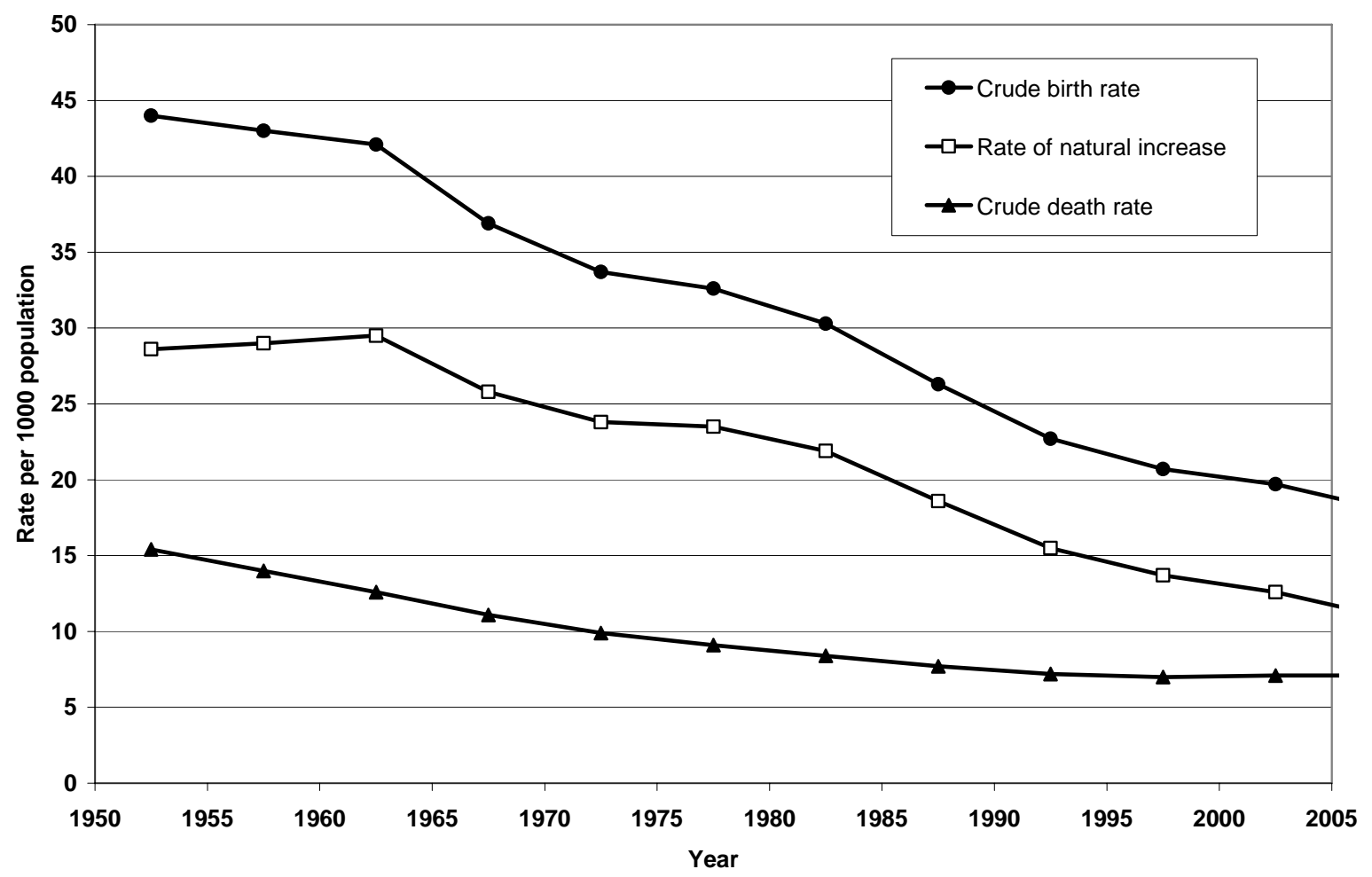


Figure 8. Total Fertility Rate and Infant Mortality Rate, Brazil 1950-2005

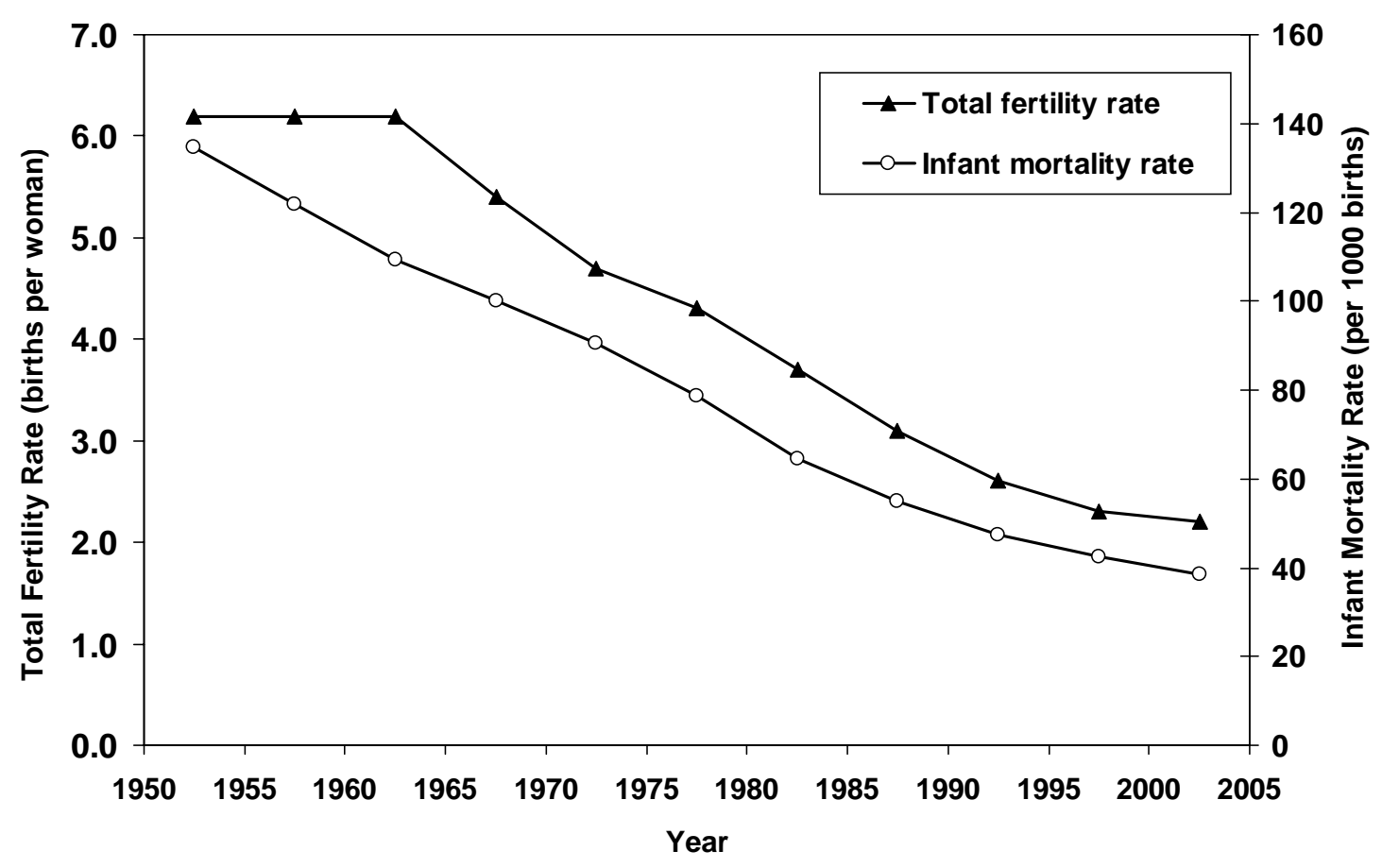


Figure 9. Cohort Size in the Brazilian Censuses from 1960 to 2000

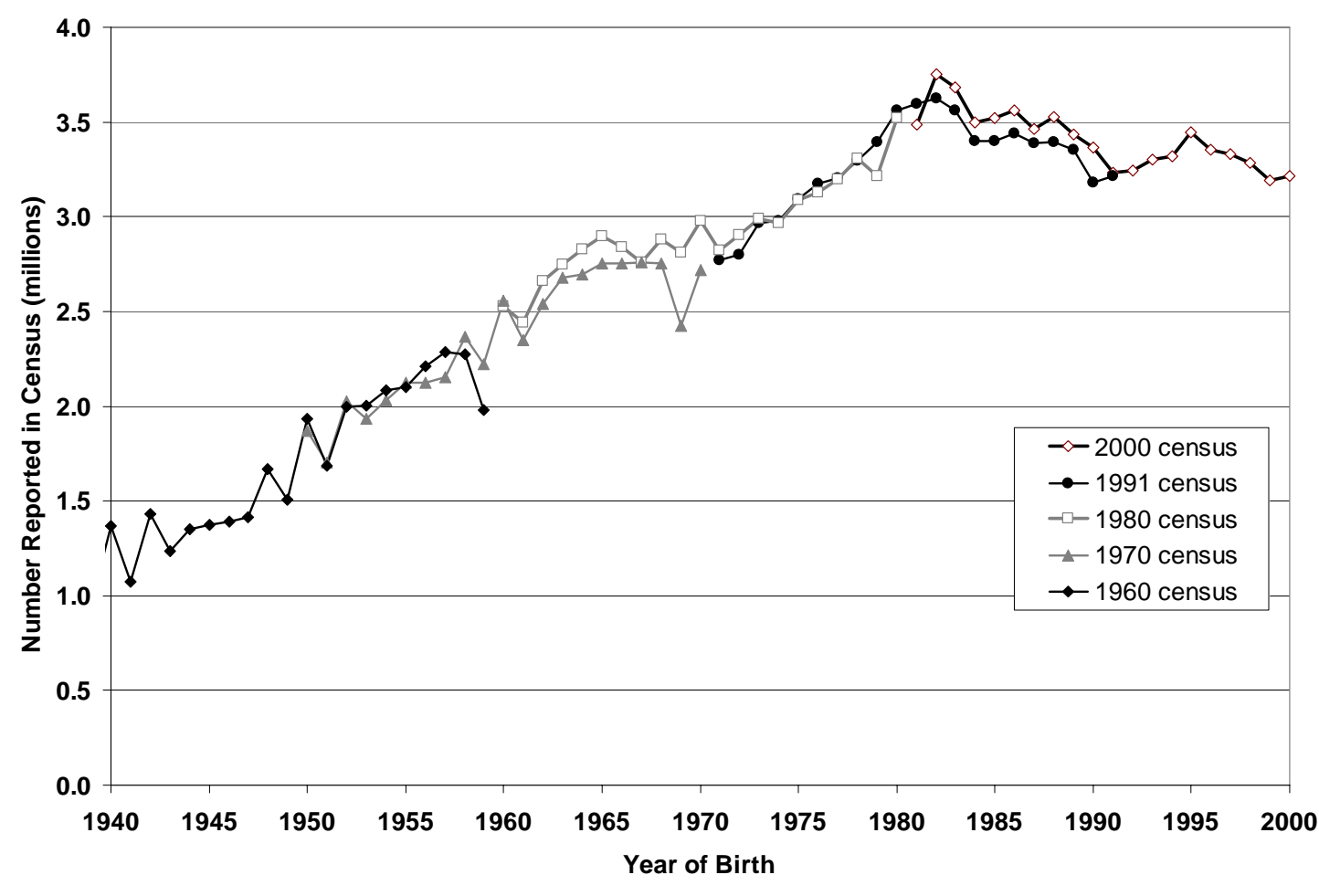


Figure 10. Growth Rate of Population Aged 9-12, 1950-2050, United Nations Medium Variant Projections
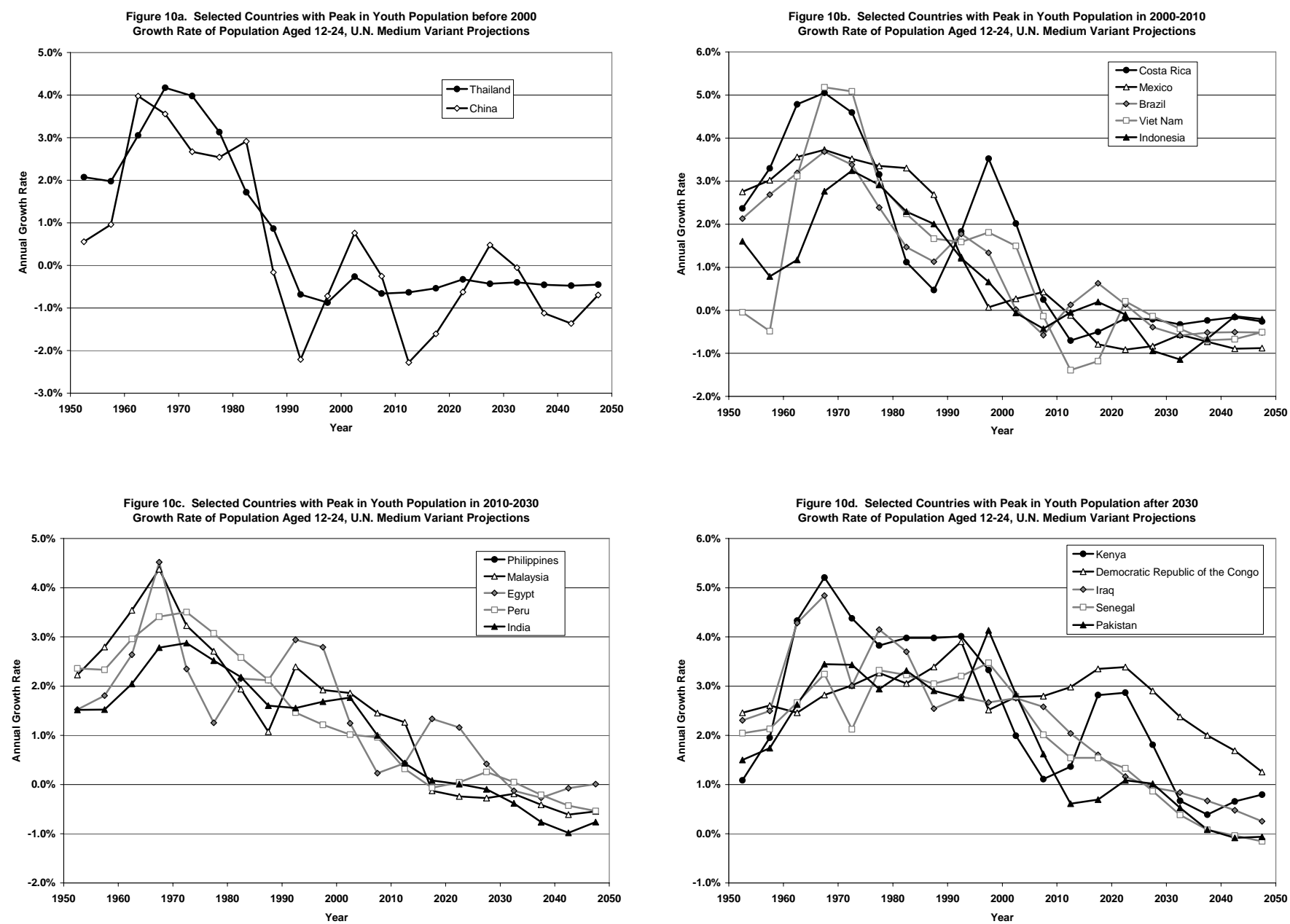
Figure 11. Percentage of Population Aged 12-24, 1950-2050, United Nations Medium Variant Projections

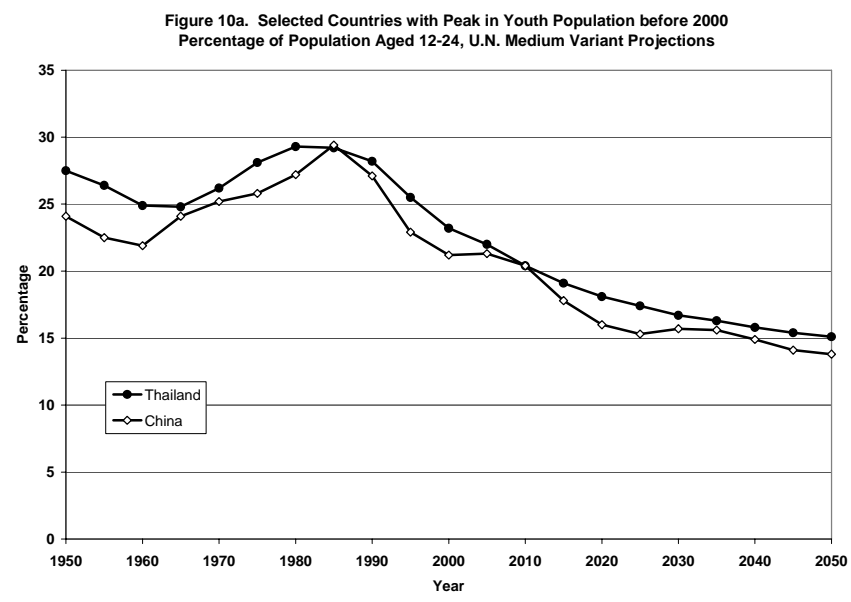

Figure 10b. Selected Countries with Peak in Youth Population in 2000-2010 Percentage of Population Aged 12-24, U.N. Medium Variant Projections

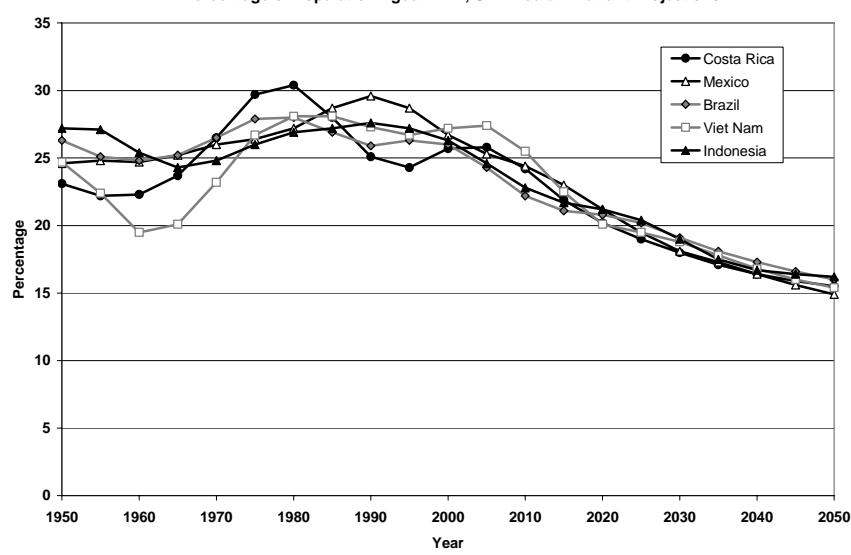

Figure 10c. Selected Countries with Peak in Youth Population in 2010-2030
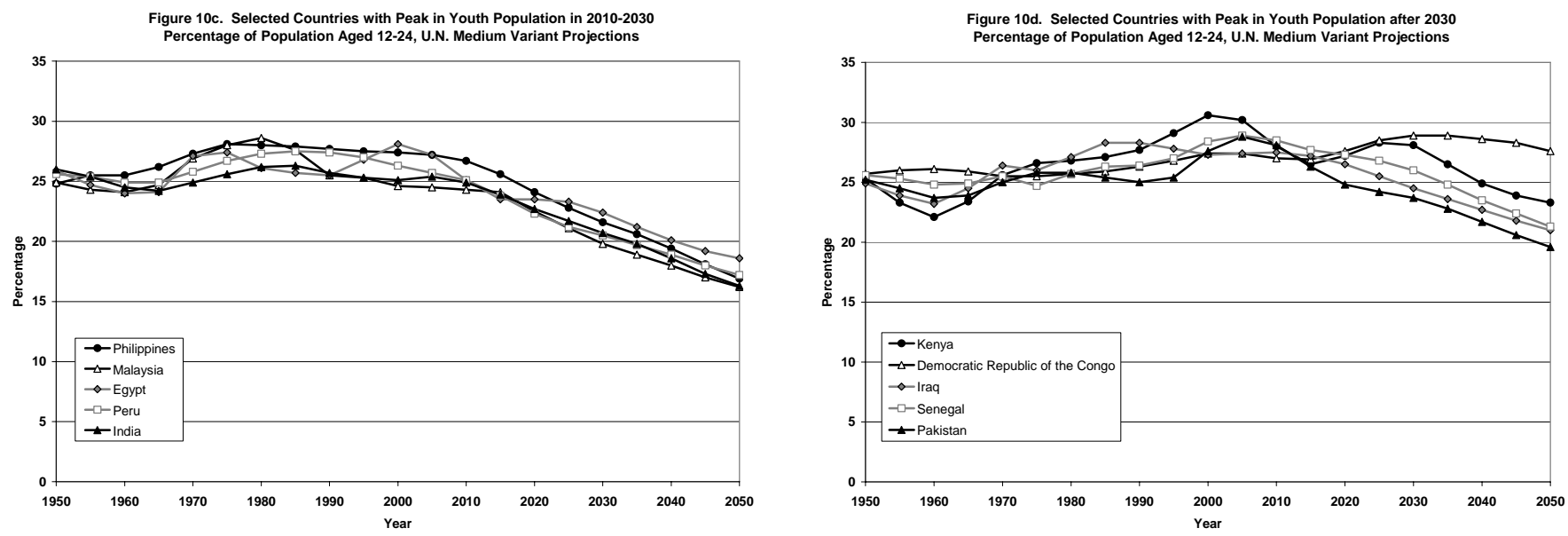
Figure 12. Ratio of Population Aged 12-24 to Population Aged 25-59, 1950-2050, United Nations Medium Variant Projections
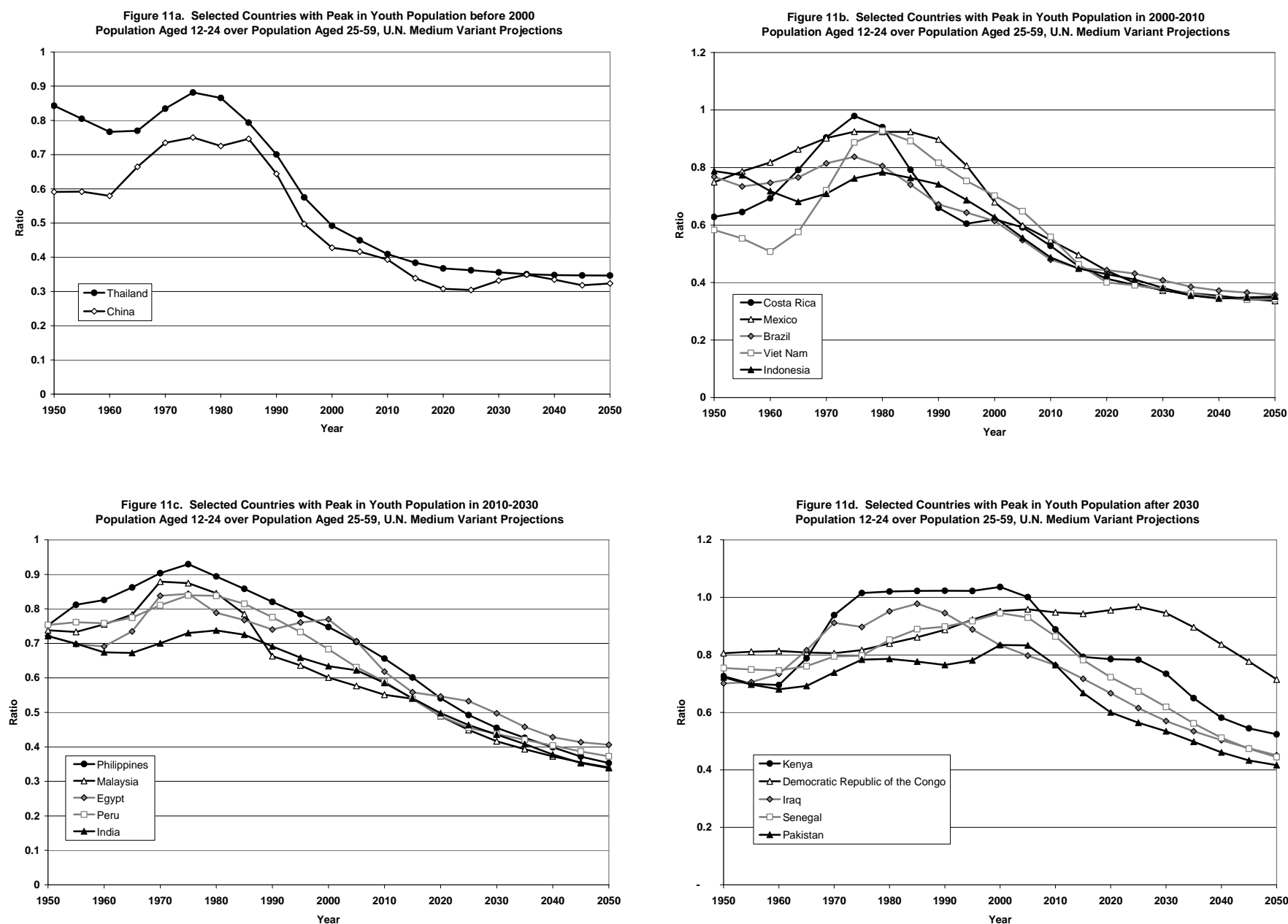
Figure 13. Average Number of Siblings of Brazilian Youth Aged 12-14, Brazil 1960-2000 Census Data

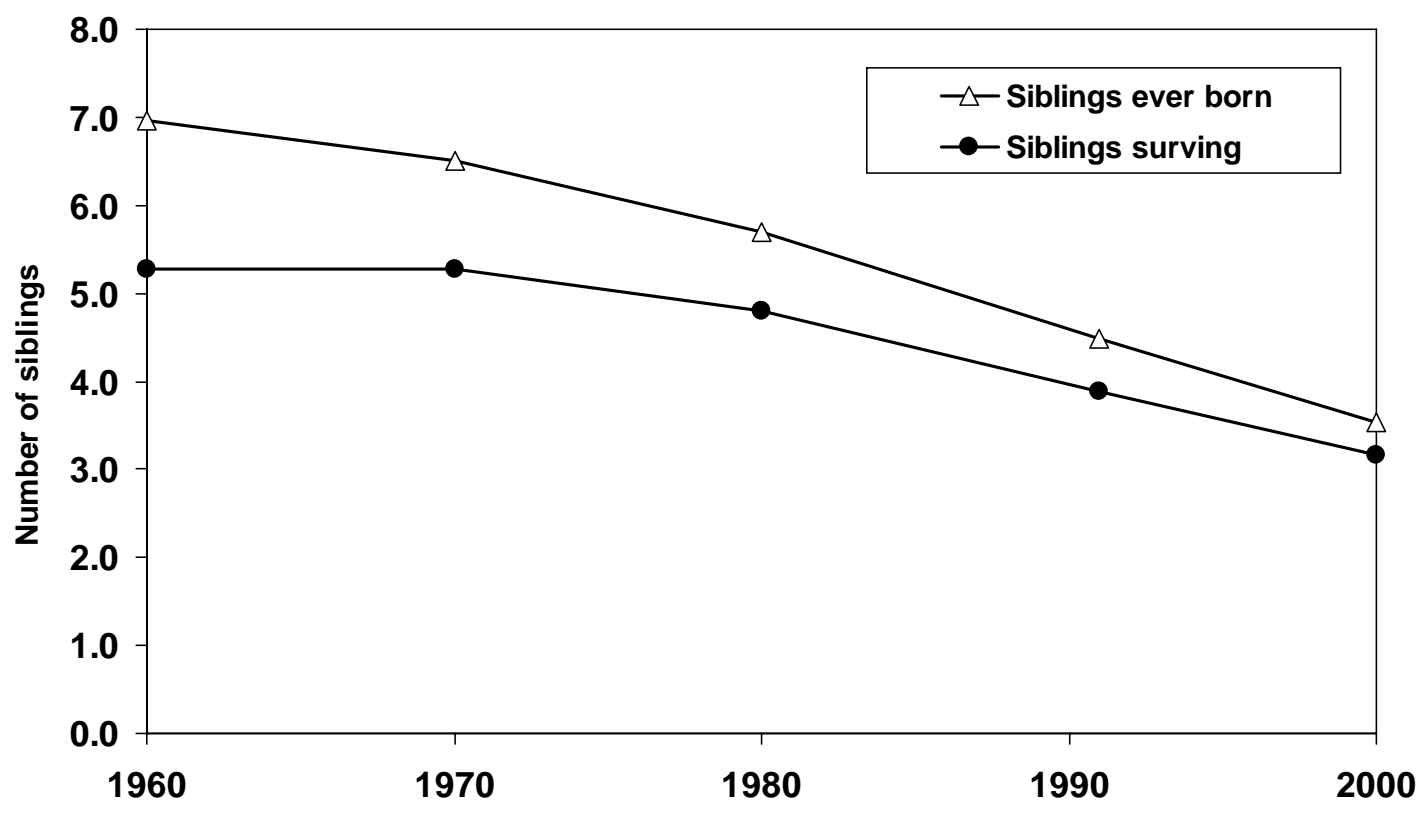


Figure 14. Measures of Youth Demography for the France, Netherlands, United Kingdom, and United States, 1950-2050, United Nations Medium Variant Projections
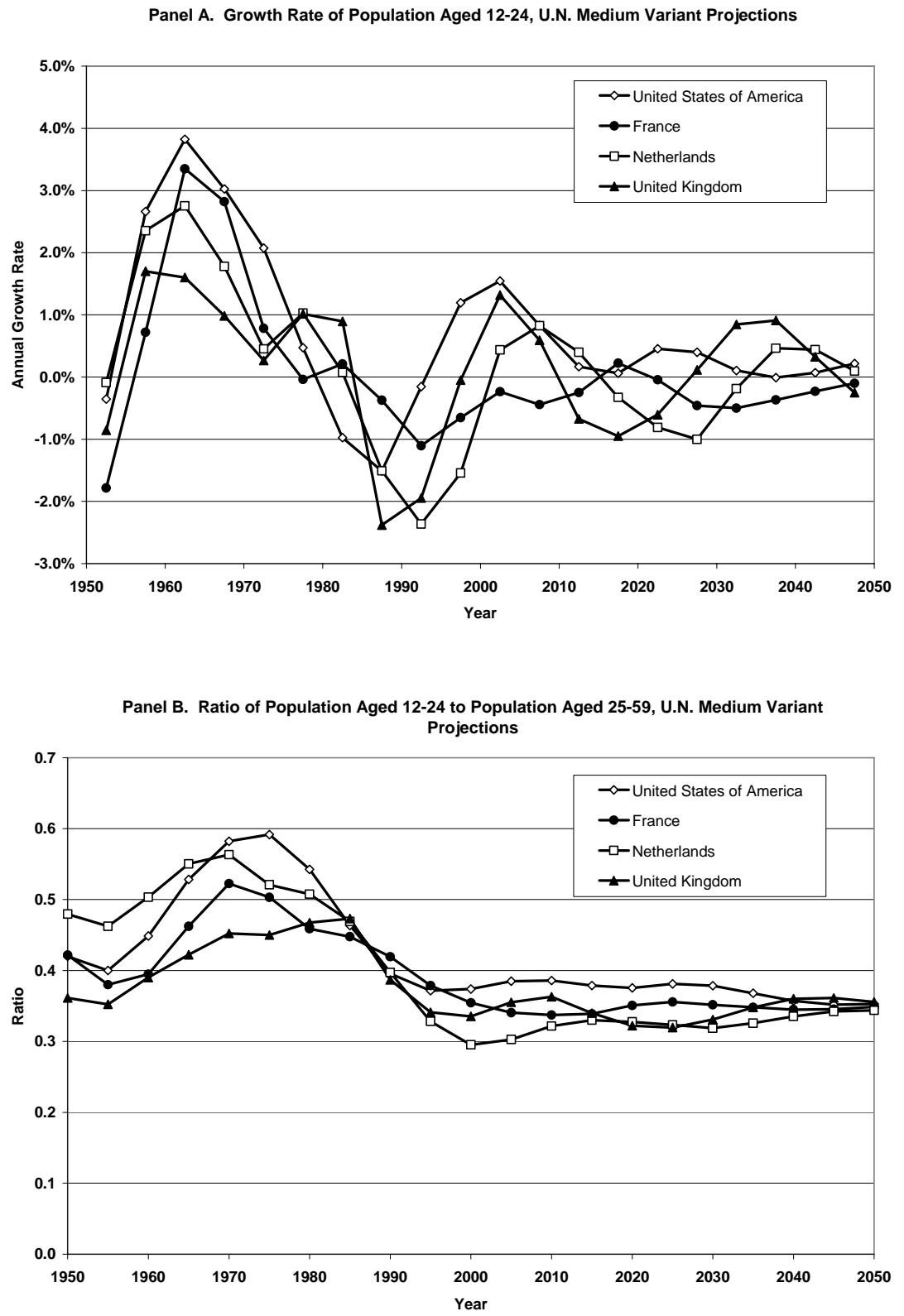


\title{
The demography of youth in developing countries and its economic implications
}

David Lam

November 2005

\section{Appendix}

\begin{abstract}
Appendix A. Assumptions used in the United Nations Population Projections
(taken from http://esa.un.org/unpp/index.asp?panel=4 on October 31, 2005)

ASSUMPTIONS UNDERLYING THE RESULTS OF THE 2004 REVISION OF WORLD POPULATION PROSPECTS
\end{abstract}

The future population of each country is projected from an estimated population for 1 July 2005. Because actual population data for 2005 are not yet available, the 2005 estimate is based upon the most recent population data available for each country, derived usually from a census or population register, updated to 2005 using all available data on fertility, mortality and international migration. In cases where very recent data are not available, estimated demographic trends are short term projections from the most recent available data. Population data from all sources are evaluated for completeness, accuracy and consistency, and adjusted where necessary.

To project population until 2050, the United Nations Population Division applies assumptions regarding future trends in fertility, mortality, and migration. Because future trends cannot be known with certainty, a number of projection variants are produced.

The 2004 Revision includes six projection variants. The results for four are available on the web. These four variants differ among themselves with respect to the assumptions made regarding the future course of fertility.

To describe the different projection variants, the assumptions made regarding fertility, mortality and international migration are described first.

\section{A. Fertility assumptions: Convergence toward total fertility below replacement}


Fertility assumptions are described in terms of the following groups of countries:

High-fertility countries: Countries that until 2005 had had no fertility reduction or only an incipient decline;

Medium-fertility countries: Countries where fertility has been declining but whose level was still above 2.1 children per woman in 2000-2005;

Low-fertility countries: Countries with total fertility at or below 2.1 children per woman in 2000-2005.

\section{Medium-fertility assumptions:}

Total fertility in all countries is assumed to converge eventually toward a level of 1.85 children per woman. However, not all countries reach this level during the projection period, that is, by 2050. The basic principle of fertility projection is the same for all countries, but projection procedures are slightly different depending on whether countries had a total fertility above or below 1.85 children per woman in 2000-2005.

Fertility in high-fertility and medium-fertility countries is assumed to follow a path derived from models of fertility decline established by the United Nations Population Division on the basis of the past experience of all countries with declining fertility during 1950-2005. The models relate the level of total fertility during a period to the average expected decline in total fertility during the next period. If the total fertility projected by a model for a country falls to 1.85 children per woman before 2050, total fertility is held constant at that level for the remainder of the projection period (that is, until 2050). That is, 1.85 children per woman represents a floor value below which the total fertility of high and medium-fertility countries is not allowed to drop before 2050. However, it is not necessary for all countries to reach the floor value by 2050. If the model of fertility change used produces a total fertility above 1.85 children per woman for 2045-2050, that value is used in projecting the population. In all cases, the projected fertility paths yielded by the models are checked against recent trends in fertility for each country. When a country's recent fertility trends deviate considerably from those consistent with the models, fertility is projected over an initial period of 5 or 10 years in such a way that it follows recent experience. The model projection takes over after that transition period. For instance, in countries where fertility has stalled or where there is no evidence of fertility decline, fertility is projected to remain constant for several more years before a declining path sets in. 
Fertility in low-fertility countries is generally assumed to remain below 2.1 children per woman during most of the projection period and reach 1.85 children per woman by 2045-2050. For countries where total fertility was below 1.85 children per woman in 2000-2005, it is assumed that over the first 5 or 10 years of the projection period fertility will follow the recently observed trends in each country. After that transition period, fertility is assumed to increase linearly at a rate of 0.07 children per woman per quinquennium. Thus, countries whose fertility is currently very low need not reach a level of 1.85 children per woman by 2050 .

\section{High-fertility assumptions:}

Under the high variant, fertility is projected to remain 0.5 children above the fertility in the medium variant over most of the projection period. By 2045-2050, fertility in the high variant is therefore half a child higher than that of the medium variant. That is, countries reaching a total fertility of 1.85 children per woman in the medium variant have a total fertility of 2.35 children per woman in the high variant at the end of the projection period.

\section{Low-fertility assumptions:}

Under the low variant, fertility is projected to remain 0.5 children below the fertility in the medium variant over most of the projection period. By 2045-2050, fertility in the low variant is therefore half a child lower than that of the medium variant. That is, countries reaching a total fertility of 1.85 children per woman in the medium variant have a total fertility of 1.35 children per woman in the low variant at the end of the projection period.

\section{Constant-fertility assumption:}

For each country, fertility remains constant at the level estimated for 2000-2005.

\section{B. Mortality assumptions: Increasing life expectancy except when affected by HIV/AIDS}

\section{Normal-mortality assumption:}

Mortality is projected on the basis of models of change of life expectancy produced by the United Nations Population Division. These models produce smaller gains the higher the life expectancy already reached. The selection of a model for each country is based on recent trends in life expectancy by sex. For countries highly affected by the HIV/AIDS epidemic, the model incorporating a slow pace of mortality decline has generally been used to project the reduction of general mortality risks not related to HIV/AIDS. 
The impact of HIV/AIDS on mortality:

For the 60 countries highly affected by the HIV/AIDS epidemic, estimates of the impact of HIV/AIDS are made by explicitly modelling the course of the epidemic and by projecting the yearly incidence of HIV infection. The model developed by the UNAIDS Reference Group on Estimates, Modelling and Projections ${ }^{2}$ is used to fit past estimates of HIV prevalence provided by UNAIDS so as to derive the parameters determining the past dynamics of the epidemic. For most countries, the model is fitted assuming that the relevant parameters have remained constant in the past. Beginning in 2005, the parameter PHI, which reflects the rate of recruitment of new individuals into the high-risk or susceptible group, is projected to decline by half every thirty years. The parameter $\mathrm{R}$, which represents the force of infection, is projected to decline in the same manner. The reduction in $\mathrm{R}$ reflects the assumption that changes in behaviour among those subject to the risk of infection, along with increases in access to treatment for those infected, will reduce the chances of transmitting the virus. The rate of mother-to-child transmission is projected to decline at varying rates, depending on each country's progress in increasing access to treatment. In addition, the component of the Reference Group model relative to the survivorship of infected children has been updated: in the 2004 Revision it is assumed that 50 per cent of children infected through mother-to-child transmission will survive to age two.

The 2004 Revision incorporates for the first time a longer survival for persons receiving treatment with highly active antiretroviral therapy (ART). The proportion of the HIV-positive population receiving treatment in each country is consistent with estimates prepared by the World Health Organization for end of $2004^{32}$. Coverage is projected to reach between 40 percent and 85 per cent by 2015, depending on the current level of coverage. It is assumed that, on average, annual survival probabilities increase to at least 80 for individuals receiving ART. Under this assumption, mean survival from the initiation of therapy is 3.1 years (median 4.5 years). In contrast, in the absence of treatment mean survival after progression to AIDS is assumed to be just one year.

\footnotetext{
2 "Improved methods and assumptions for estimation of the HIV/AIDS epidemic and its impact: Recommendations of the UNAIDS Reference Group on Estimates, Modelling and Projections". AIDS, vol. 16, pp. W1-W14 (UNAIDS Reference Group on Estimates, Modelling and Projections, 2002).

${ }^{3}$ World Health Organization. “3 by 5” Progress Report, December 2004. WHO and UNAIDS.
} 


\section{International migration assumptions}

\section{Normal-migration assumption:}

The future path of international migration is set on the basis of past international migration estimates and an assessment of the policy stance of countries with regard to future international migration flows.

\section{The projection variants}

Table 1 presents in a schematic way the different assumptions underlying the four projection variants. As shown, the four variants (low, medium, high and constant-fertility) share the same assumptions regarding mortality and international migration. They differ among themselves only with respect to the assumptions regarding fertility. A comparison of their results allows therefore an assessment of the effects that different fertility paths have on other demographic parameters.

Table 1. Projection variants in terms of assumptions for fertility, mortality and international migration

\begin{tabular}{|c|c|c|c|}
\hline & \multicolumn{3}{|c|}{ Assumptions } \\
\hline Projection variant & Fertility & Mortality & $\begin{array}{l}\text { International } \\
\text { migration }\end{array}$ \\
\hline Low & Low & Normal & Normal \\
\hline Medium & Medium & Normal & Normal \\
\hline High & High & Normal & Normal \\
\hline Constant-fertility & Constant & Normal & Normal \\
\hline Constant-mortality & Medium & Constant & Normal \\
\hline Zero-migration & Medium & Normal & Zero \\
\hline
\end{tabular}

\section{E. Methodological changes made for the 2004 Revision}

In the medium variant, the fertility of countries with a total fertility below 1.85 children per woman in 20002005 is projected first by continuing recent trends and then by increasing fertility linearly at a rate of 0.07 children per woman per quinquennium. These countries do not necessarily reach a level of 1.85 children per woman by 2050 . 
In the 2004 Revision, additional models of mortality change have been used to capture the diversity of historical experience in the rise of life expectancy. Specifically, very slow and very fast models of change have been developed and added to the previously existing slow, medium and fast models.

The impact of HIV/AIDS on mortality is modelled explicitly for all countries that had adult HIV prevalence of one per cent or greater in 2003.

Treatment with antiretroviral therapy is explicitly incorporated into the projection of HIV/AIDS for affected countries. In addition, the rate of mother-to-child transmission of HIV is projected to decline at a rate consistent with projected progress in expanding access to treatment. 


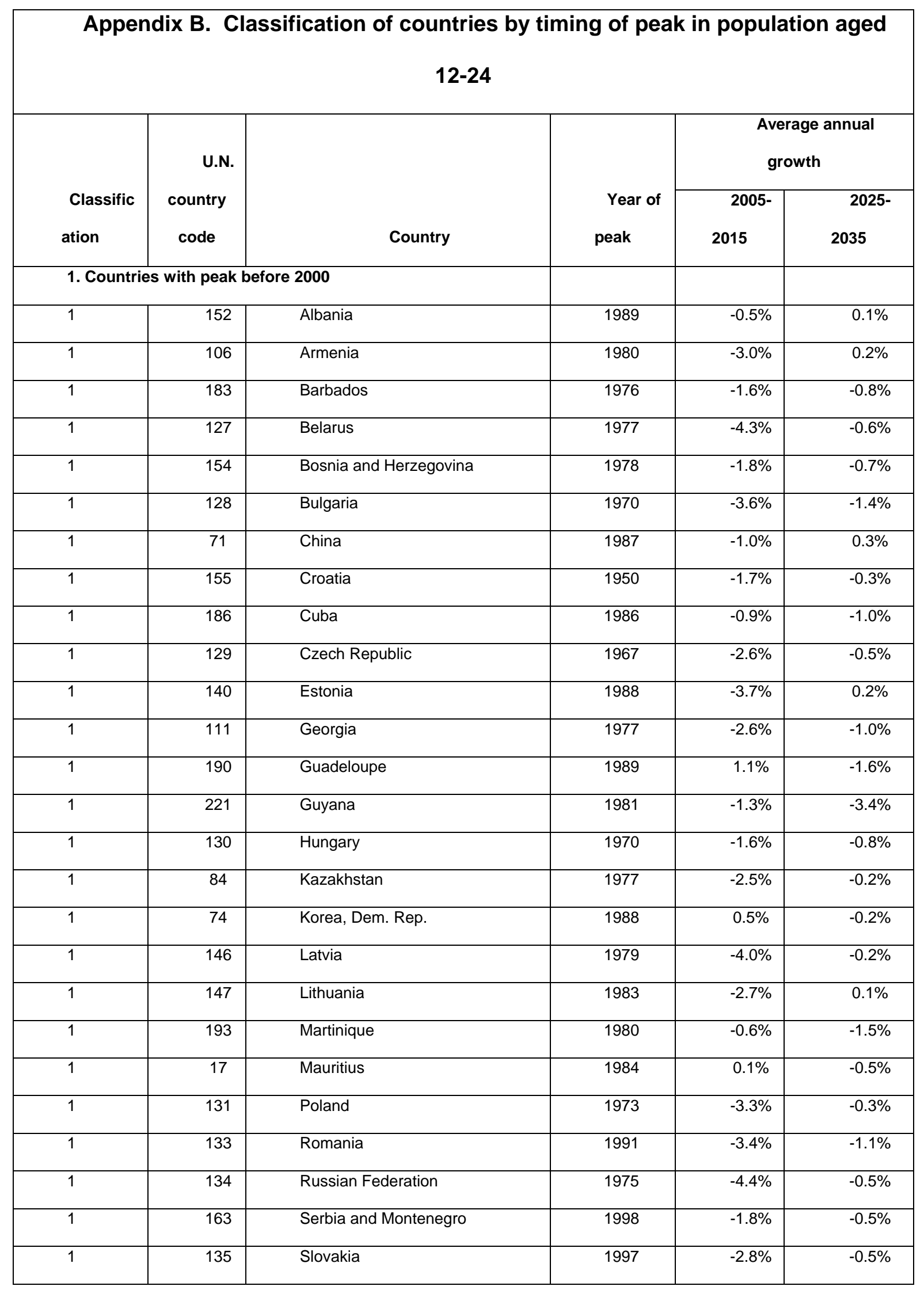




\begin{tabular}{|c|c|c|c|c|c|}
\hline 1 & 164 & Slovenia & 1994 & $-2.9 \%$ & $-0.7 \%$ \\
\hline 1 & 224 & Suriname & 1985 & $-0.9 \%$ & $-1.3 \%$ \\
\hline 1 & 166 & TFYR Macedonia & 1979 & $-1.7 \%$ & $-0.2 \%$ \\
\hline 1 & 103 & Thailand & 1990 & $-0.6 \%$ & $-0.4 \%$ \\
\hline 1 & 136 & Ukraine & 1976 & $-4.0 \%$ & $-0.9 \%$ \\
\hline \multicolumn{6}{|c|}{ 2. Countries with peak between 2000 and 2010} \\
\hline 2 & 38 & Algeria & 2005 & $-1.3 \%$ & $0.8 \%$ \\
\hline 2 & 213 & Argentina & 2030 & $0.3 \%$ & $0.1 \%$ \\
\hline 2 & 107 & Azerbaijan & 2007 & $-1.3 \%$ & $0.7 \%$ \\
\hline 2 & 46 & Botswana & 2008 & $-0.2 \%$ & $0.0 \%$ \\
\hline 2 & 215 & Brazil & 2024 & $-0.3 \%$ & $-0.4 \%$ \\
\hline 2 & 216 & Chile & 2009 & $-0.1 \%$ & $0.0 \%$ \\
\hline 2 & 205 & Costa Rica & 2008 & $0.0 \%$ & $-0.2 \%$ \\
\hline 2 & 188 & Dominican Republic & 2027 & $0.2 \%$ & $-0.2 \%$ \\
\hline 2 & 238 & Fiji & 2002 & $-0.2 \%$ & $-0.8 \%$ \\
\hline 2 & 191 & Haiti & 2030 & $0.0 \%$ & $0.1 \%$ \\
\hline 2 & 97 & Indonesia & 2002 & $-0.3 \%$ & $-1.0 \%$ \\
\hline 2 & 83 & Iran & 2004 & $-2.5 \%$ & $0.9 \%$ \\
\hline 2 & 192 & Jamaica & 2011 & $0.4 \%$ & $-0.7 \%$ \\
\hline 2 & 85 & Kyrgyzstan & 2008 & $-0.1 \%$ & $-0.5 \%$ \\
\hline 2 & 116 & Lebanon & 2012 & $0.4 \%$ & $0.0 \%$ \\
\hline 2 & 47 & Lesotho & 2006 & $-0.8 \%$ & $-0.1 \%$ \\
\hline 2 & 40 & Libya & 2030 & $-1.1 \%$ & $0.1 \%$ \\
\hline 2 & 209 & Mexico & 2012 & $0.2 \%$ & $-0.7 \%$ \\
\hline 2 & 247 & Micronesia (Federated States of) & 2024 & $-0.5 \%$ & $-1.3 \%$ \\
\hline 2 & 76 & Mongolia & 2006 & $-0.9 \%$ & $-0.6 \%$ \\
\hline 2 & 41 & Morocco & 2029 & $-0.2 \%$ & $0.0 \%$ \\
\hline 2 & 100 & Myanmar & 2009 & $-0.1 \%$ & $-0.4 \%$ \\
\hline 2 & 132 & Republic of Moldova & 2002 & $-3.6 \%$ & $-0.3 \%$ \\
\hline 2 & 198 & Saint Lucia & 2006 & $-0.7 \%$ & $-0.1 \%$ \\
\hline 2 & 199 & Saint Vincent and the Grenadines & 2001 & $-2.2 \%$ & $-1.3 \%$ \\
\hline 2 & 36 & Sao Tome and Principe & 2029 & $0.5 \%$ & $0.1 \%$ \\
\hline 2 & 49 & South Africa & 2014 & $0.3 \%$ & $-0.4 \%$ \\
\hline 2 & 89 & Sri Lanka & 2000 & $-1.1 \%$ & $-0.4 \%$ \\
\hline Classific & U.N. & Country & Year of & & \\
\hline
\end{tabular}




\begin{tabular}{|c|c|c|c|c|c|}
\hline \multirow[b]{2}{*}{ ation } & \multirow[b]{2}{*}{$\begin{array}{l}\text { country } \\
\text { code }\end{array}$} & & \multirow[b]{2}{*}{ peak } & \multicolumn{2}{|c|}{ growth } \\
\hline & & & & $\begin{array}{l}\text { 2005- } \\
2015\end{array}$ & $\begin{array}{l}2025- \\
2035\end{array}$ \\
\hline 2 & 50 & Swaziland & 2008 & $-0.2 \%$ & $0.5 \%$ \\
\hline 2 & 259 & Tonga & 2004 & $-0.4 \%$ & $-1.9 \%$ \\
\hline 2 & 200 & Trinidad and Tobago & 2001 & $-3.4 \%$ & $-0.2 \%$ \\
\hline 2 & 43 & Tunisia & 2004 & $-1.5 \%$ & $-0.1 \%$ \\
\hline 2 & 122 & Turkey & 2020 & $0.4 \%$ & $-0.3 \%$ \\
\hline 2 & 91 & Turkmenistan & 2008 & $-0.2 \%$ & $0.2 \%$ \\
\hline 2 & 92 & Uzbekistan & 2009 & $0.1 \%$ & $0.0 \%$ \\
\hline 2 & 104 & Viet Nam & 2007 & $-0.5 \%$ & $-0.2 \%$ \\
\hline 2 & 26 & Zimbabwe & 2008 & $0.0 \%$ & $0.3 \%$ \\
\hline \multicolumn{6}{|c|}{ 3. Countries with peak between 2010 and 2030} \\
\hline 3 & 108 & Bahrain & 2015 & $1.9 \%$ & $-0.4 \%$ \\
\hline 3 & 80 & Bangladesh & 2039 & $1.1 \%$ & $0.4 \%$ \\
\hline 3 & 204 & Belize & 2027 & $1.2 \%$ & $-0.1 \%$ \\
\hline 3 & 214 & Bolivia & 2027 & $1.8 \%$ & $-0.1 \%$ \\
\hline 3 & 29 & Cameroon & 2041 & $1.5 \%$ & $0.4 \%$ \\
\hline 3 & 217 & Colombia & 2016 & $0.9 \%$ & $-0.1 \%$ \\
\hline 3 & 218 & Ecuador & 2019 & $0.7 \%$ & $-0.3 \%$ \\
\hline 3 & 39 & Egypt & 2031 & $0.3 \%$ & $0.3 \%$ \\
\hline 3 & 206 & El Salvador & 2024 & $1.1 \%$ & $-0.1 \%$ \\
\hline 3 & 208 & Honduras & 2032 & $1.7 \%$ & $0.2 \%$ \\
\hline 3 & 82 & India & 2024 & $0.8 \%$ & $-0.2 \%$ \\
\hline 3 & 113 & Israel & 2025 & $1.3 \%$ & $-0.2 \%$ \\
\hline 3 & 114 & Jordan & 2021 & $1.9 \%$ & $0.0 \%$ \\
\hline 3 & 99 & Malaysia & 2016 & $1.5 \%$ & $-0.2 \%$ \\
\hline 3 & 237 & Melanesia & 2043 & $2.1 \%$ & $0.3 \%$ \\
\hline 3 & 243 & Micronesia & 2026 & $1.1 \%$ & $-0.1 \%$ \\
\hline 3 & 210 & Nicaragua & 2030 & $1.1 \%$ & $0.0 \%$ \\
\hline 3 & 211 & Panama & 2027 & $1.0 \%$ & $0.0 \%$ \\
\hline 3 & 240 & Papua New Guinea & 2044 & $2.5 \%$ & $0.4 \%$ \\
\hline 3 & 223 & Peru & 2033 & $0.7 \%$ & $0.2 \%$ \\
\hline 3 & 101 & Philippines & 2018 & $1.1 \%$ & $-0.2 \%$ \\
\hline 3 & 251 & Polynesia & 2014 & $0.8 \%$ & $-0.9 \%$ \\
\hline
\end{tabular}




\begin{tabular}{|c|c|c|c|c|c|}
\hline 3 & 119 & Qatar & 2050 & $1.7 \%$ & $0.1 \%$ \\
\hline 3 & 19 & Réunion & 2026 & $0.7 \%$ & $-0.2 \%$ \\
\hline 3 & 257 & Samoa & 2017 & $1.9 \%$ & $-2.6 \%$ \\
\hline 3 & 241 & Solomon Islands & 2042 & $2.0 \%$ & $0.2 \%$ \\
\hline 3 & 42 & Sudan & 2049 & $1.9 \%$ & $0.4 \%$ \\
\hline 3 & 121 & Syrian Arab Republic & 2030 & $0.5 \%$ & $0.2 \%$ \\
\hline 3 & 225 & Uruguay & 2017 & $0.5 \%$ & $-0.5 \%$ \\
\hline 3 & 242 & Vanuatu & 2041 & $1.6 \%$ & $0.4 \%$ \\
\hline 3 & 226 & Venezuela & 2030 & $0.6 \%$ & $0.1 \%$ \\
\hline \multicolumn{6}{|c|}{ 4. Countries with peak after 2030} \\
\hline 4 & 79 & Afghanistan & 2050 & $3.7 \%$ & $2.8 \%$ \\
\hline 4 & 28 & Angola & 2050 & $2.7 \%$ & $2.4 \%$ \\
\hline 4 & 52 & Benin & 2050 & $2.6 \%$ & $1.8 \%$ \\
\hline 4 & 81 & Bhutan & 2050 & $1.4 \%$ & $1.2 \%$ \\
\hline 4 & 53 & Burkina Faso & 2050 & $2.9 \%$ & $2.4 \%$ \\
\hline 4 & 9 & Burundi & 2050 & $1.8 \%$ & $3.5 \%$ \\
\hline 4 & 95 & Cambodia & 2035 & $0.1 \%$ & $1.0 \%$ \\
\hline 4 & 54 & Cape Verde & 2037 & $0.8 \%$ & $0.6 \%$ \\
\hline 4 & 30 & Central African Republic & 2050 & $1.9 \%$ & $0.9 \%$ \\
\hline 4 & 31 & Chad & 2050 & $2.9 \%$ & $3.0 \%$ \\
\hline 4 & 10 & Comoros & 2050 & $2.1 \%$ & $0.6 \%$ \\
\hline 4 & 32 & Congo & 2050 & $3.3 \%$ & $2.9 \%$ \\
\hline 4 & 55 & Côte d'Ivoire & 2050 & $1.5 \%$ & $0.7 \%$ \\
\hline 4 & 33 & Dem. Rep. Congo & 2050 & $2.9 \%$ & $2.7 \%$ \\
\hline 4 & 11 & Djibouti & 2050 & $1.8 \%$ & $0.7 \%$ \\
\hline 4 & 96 & East Timor & 2050 & $0.9 \%$ & $2.2 \%$ \\
\hline 4 & 34 & Equatorial Guinea & 2050 & $2.7 \%$ & $2.1 \%$ \\
\hline
\end{tabular}




\begin{tabular}{|c|c|c|c|c|c|}
\hline \multirow[b]{2}{*}{$\begin{array}{l}\text { Classific } \\
\text { ation }\end{array}$} & \multirow{2}{*}{$\begin{array}{c}\text { U. } \\
\mathrm{N} . \\
\text { country } \\
\text { code }\end{array}$} & \multirow[b]{2}{*}{ Country } & \multirow[b]{2}{*}{$\begin{array}{l}\text { Year of } \\
\text { peak }\end{array}$} & \multicolumn{2}{|c|}{$\begin{array}{l}\text { Average annual } \\
\text { growth }\end{array}$} \\
\hline & & & & $\begin{array}{l}2005- \\
2015\end{array}$ & $\begin{array}{l}2025- \\
2035\end{array}$ \\
\hline 4 & 12 & Eritrea & 2050 & $2.9 \%$ & $1.5 \%$ \\
\hline 4 & 13 & Ethiopia & 2050 & $2.6 \%$ & $1.5 \%$ \\
\hline 4 & $\begin{array}{l}22 \\
0\end{array}$ & French Guiana & 2040 & $2.7 \%$ & $0.6 \%$ \\
\hline 4 & 35 & Gabon & 2041 & $1.8 \%$ & $0.5 \%$ \\
\hline 4 & 56 & Gambia & 2050 & $2.6 \%$ & $0.6 \%$ \\
\hline 4 & 57 & Ghana & 2050 & $1.3 \%$ & $0.6 \%$ \\
\hline 4 & $\begin{array}{l}20 \\
7\end{array}$ & Guatemala & 2038 & $2.4 \%$ & $0.8 \%$ \\
\hline 4 & 58 & Guinea & 2050 & $2.8 \%$ & $1.8 \%$ \\
\hline 4 & 59 & Guinea-Bissau & 2050 & $3.3 \%$ & $2.9 \%$ \\
\hline 4 & $\begin{array}{r}11 \\
2\end{array}$ & Iraq & 2050 & $2.4 \%$ & $0.9 \%$ \\
\hline 4 & 14 & Kenya & 2050 & $1.2 \%$ & $1.4 \%$ \\
\hline 4 & 98 & Laos & 2042 & $2.0 \%$ & $0.7 \%$ \\
\hline 4 & 60 & Liberia & 2050 & $2.7 \%$ & $2.7 \%$ \\
\hline 4 & 15 & Madagascar & 2050 & $3.0 \%$ & $1.3 \%$ \\
\hline 4 & 16 & Malawi & 2050 & $3.3 \%$ & $1.8 \%$ \\
\hline 4 & 86 & Maldives & 2037 & $1.8 \%$ & $0.9 \%$ \\
\hline 4 & 61 & Mali & 2050 & $3.1 \%$ & $2.5 \%$ \\
\hline 4 & 62 & Mauritania & 2050 & $2.7 \%$ & $1.4 \%$ \\
\hline 4 & 18 & Mozambique & 2050 & $2.4 \%$ & $1.1 \%$ \\
\hline 4 & 48 & Namibia & 2040 & $2.1 \%$ & $1.1 \%$ \\
\hline 4 & 87 & Nepal & 2043 & $2.0 \%$ & $0.7 \%$ \\
\hline 4 & 63 & Niger & 2050 & $3.6 \%$ & $2.9 \%$ \\
\hline 4 & 64 & Nigeria & 2050 & $2.2 \%$ & $0.9 \%$ \\
\hline 4 & $\begin{array}{r}11 \\
8\end{array}$ & Oman & 2038 & $0.8 \%$ & $0.9 \%$ \\
\hline 4 & 88 & Pakistan & 2039 & $1.3 \%$ & $0.9 \%$ \\
\hline 4 & 11 & Palestinian Territory & 2050 & $3.6 \%$ & $1.2 \%$ \\
\hline
\end{tabular}




\begin{tabular}{|c|c|c|c|c|c|}
\hline & 7 & & & & \\
\hline 4 & $\begin{array}{r}22 \\
2\end{array}$ & Paraguay & 2049 & $1.6 \%$ & $0.6 \%$ \\
\hline 4 & 20 & Rwanda & 2050 & $0.9 \%$ & $1.2 \%$ \\
\hline 4 & 66 & Senegal & 2040 & $1.9 \%$ & $0.7 \%$ \\
\hline 4 & 67 & Sierra Leone & 2050 & $2.5 \%$ & $2.2 \%$ \\
\hline 4 & 22 & Somalia & 2050 & $3.2 \%$ & $1.7 \%$ \\
\hline 4 & 90 & Tajikistan & 2035 & $1.0 \%$ & $0.6 \%$ \\
\hline 4 & 24 & Tanzania & 2039 & $1.8 \%$ & $0.5 \%$ \\
\hline 4 & 68 & Togo & 2048 & $2.5 \%$ & $1.0 \%$ \\
\hline 4 & 23 & Uganda & 2050 & $3.4 \%$ & $3.7 \%$ \\
\hline 4 & 44 & Western Sahara & 2038 & $2.7 \%$ & $2.3 \%$ \\
\hline 4 & $\begin{array}{r}12 \\
4\end{array}$ & Yemen & 2050 & $2.7 \%$ & $2.0 \%$ \\
\hline 4 & 25 & Zambia & 2050 & $1.9 \%$ & $1.4 \%$ \\
\hline
\end{tabular}




\section{Appendix C. Size of Population Aged 12-24 from 1950 to 2050, United}

\section{Category 1: Peak before 2000}
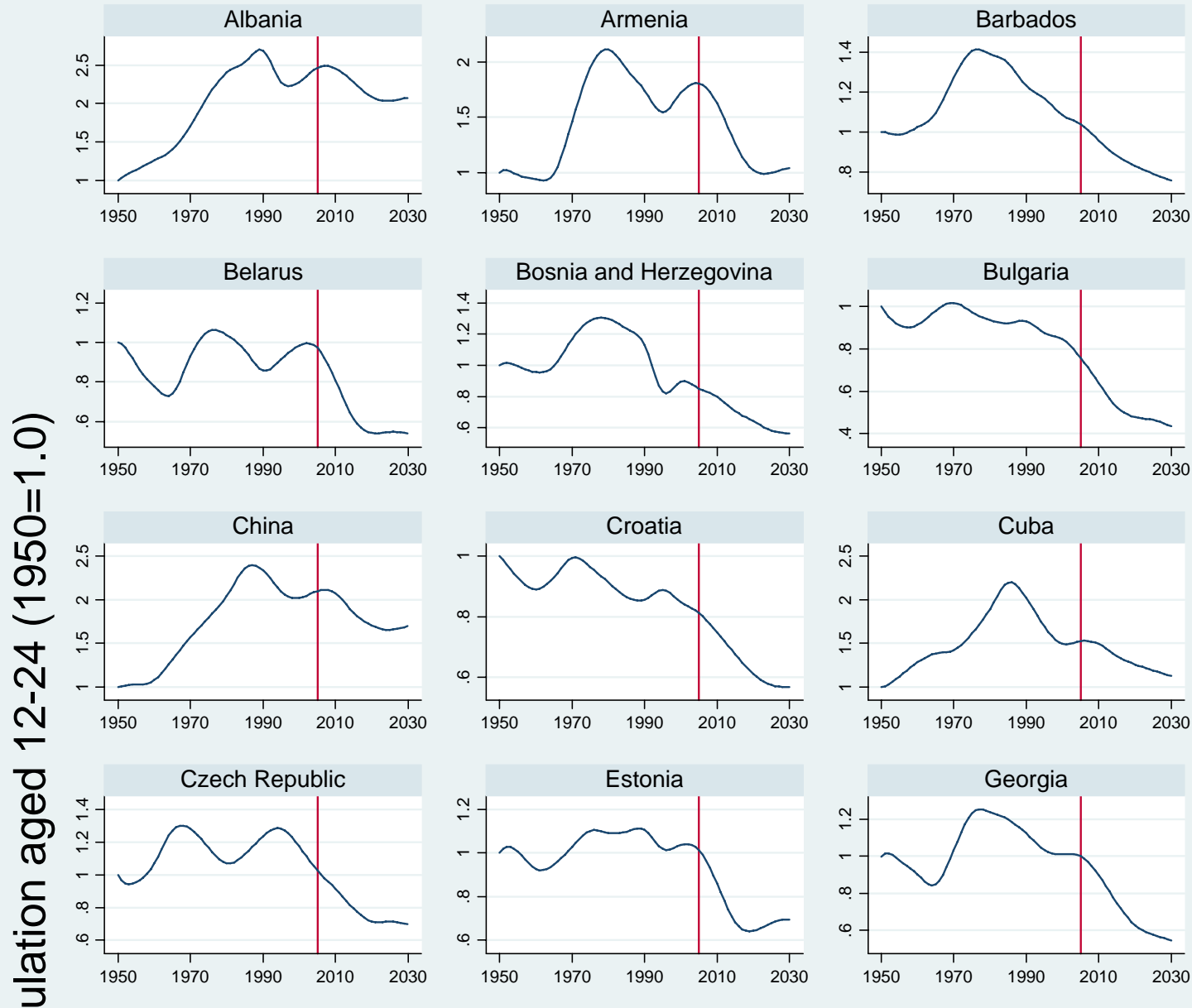

응
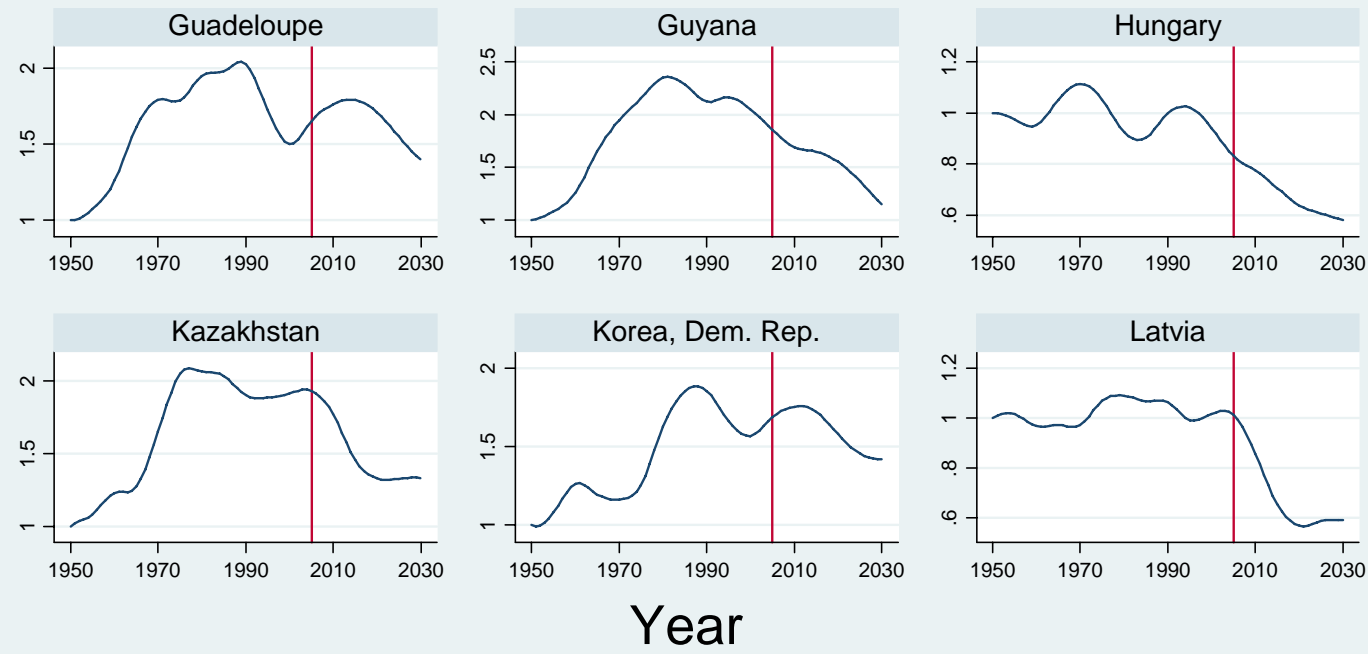

United Nations Medium Variant Projections 


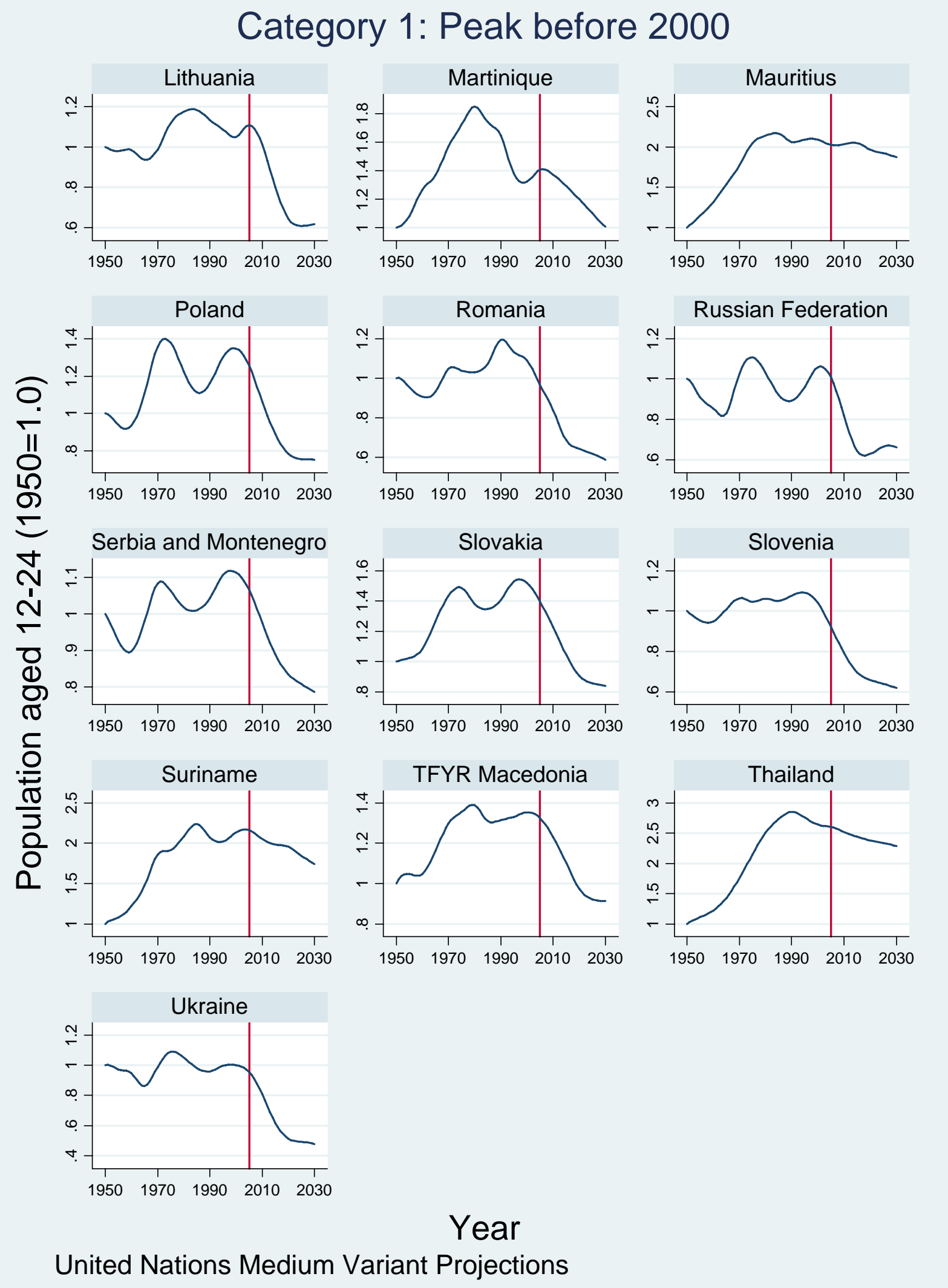




\section{Category 2: Peak 2000-2010}
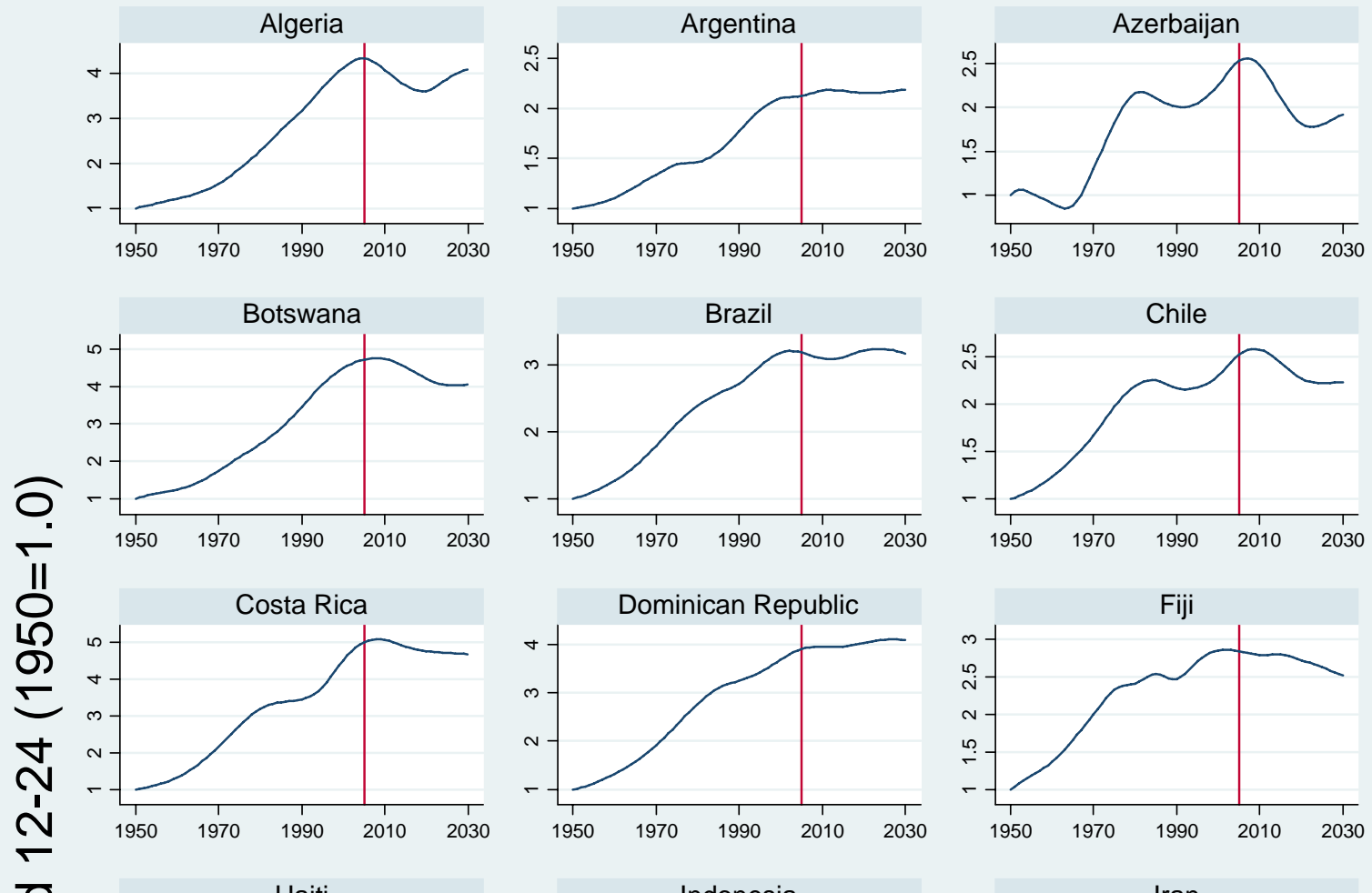

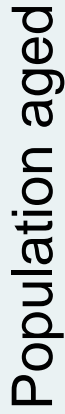
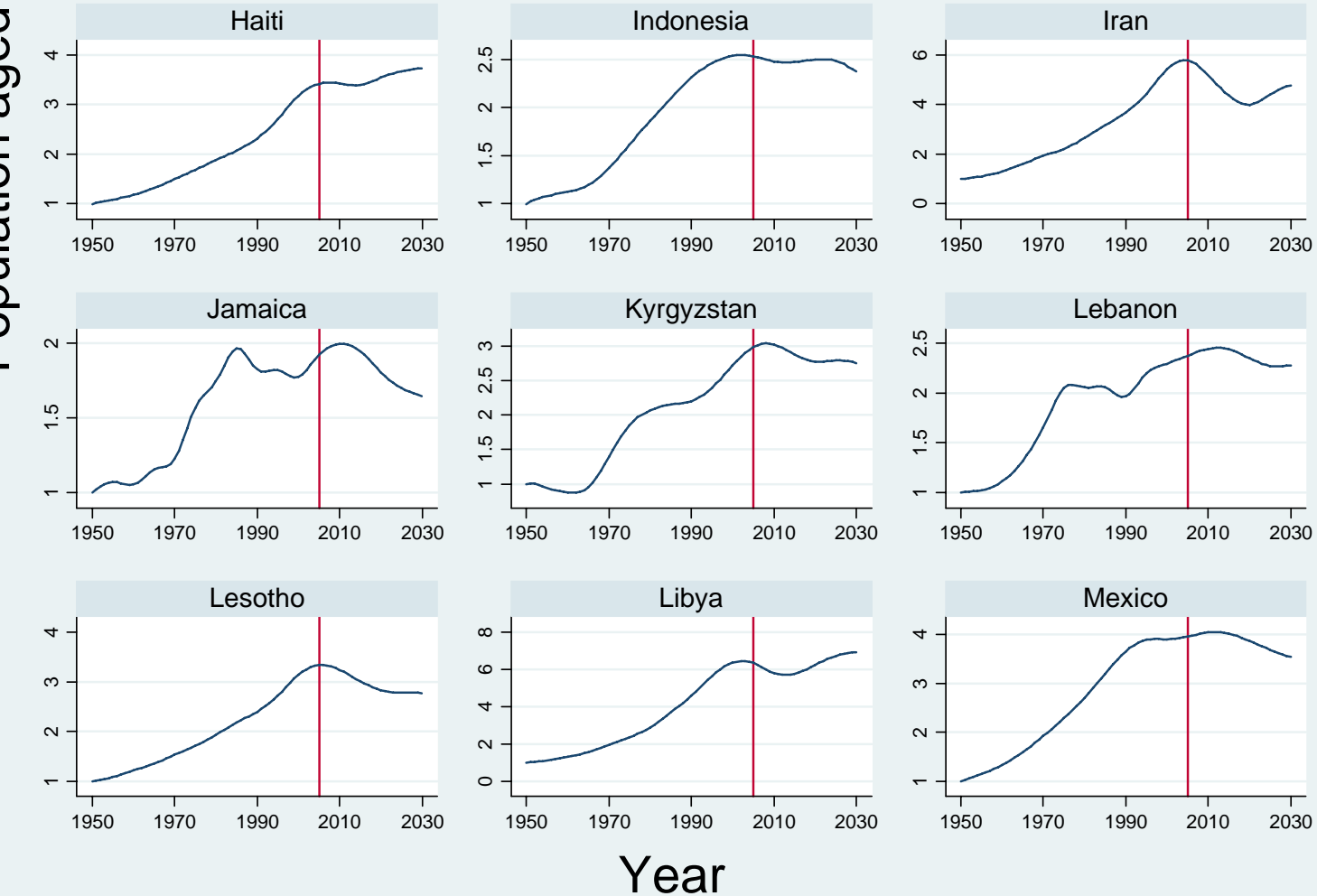

United Nations Medium Variant Projections 


\section{Category 3: Peak 2000-2010}
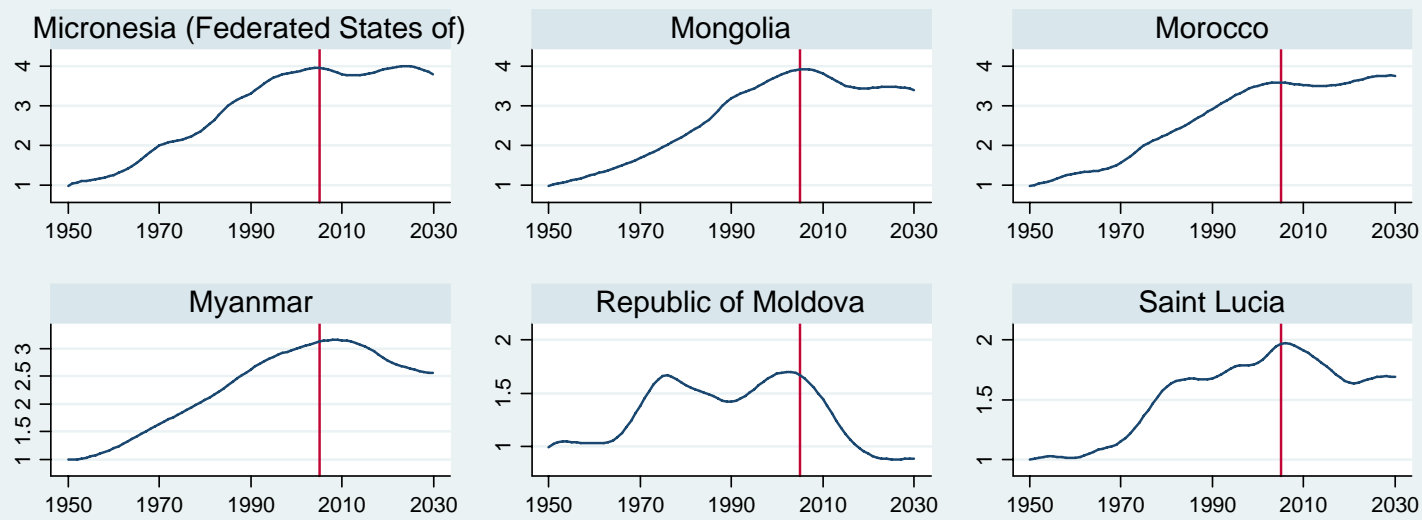

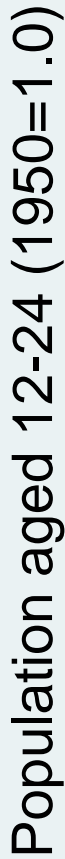

Saint Vincent and the Grenadines
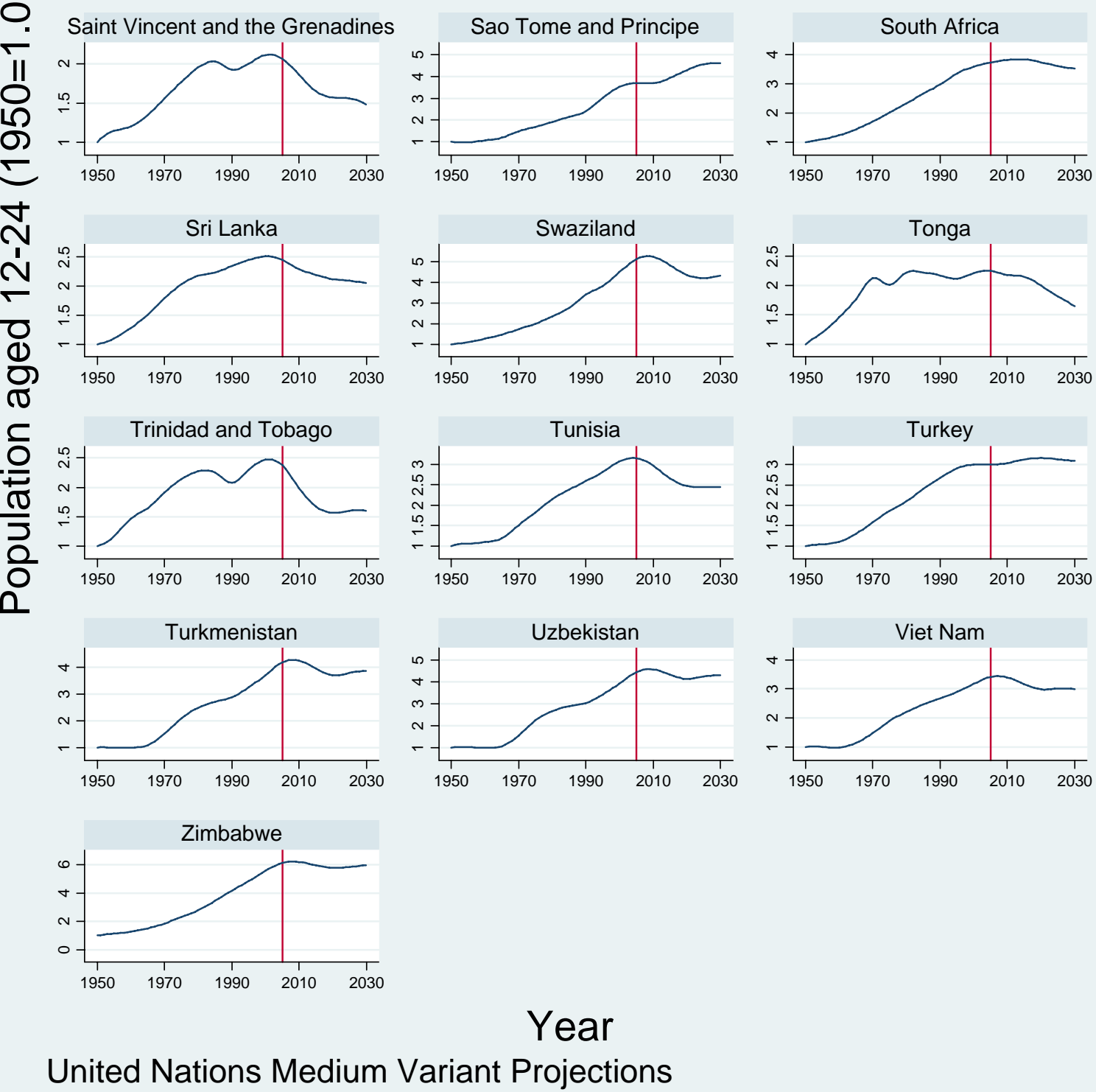


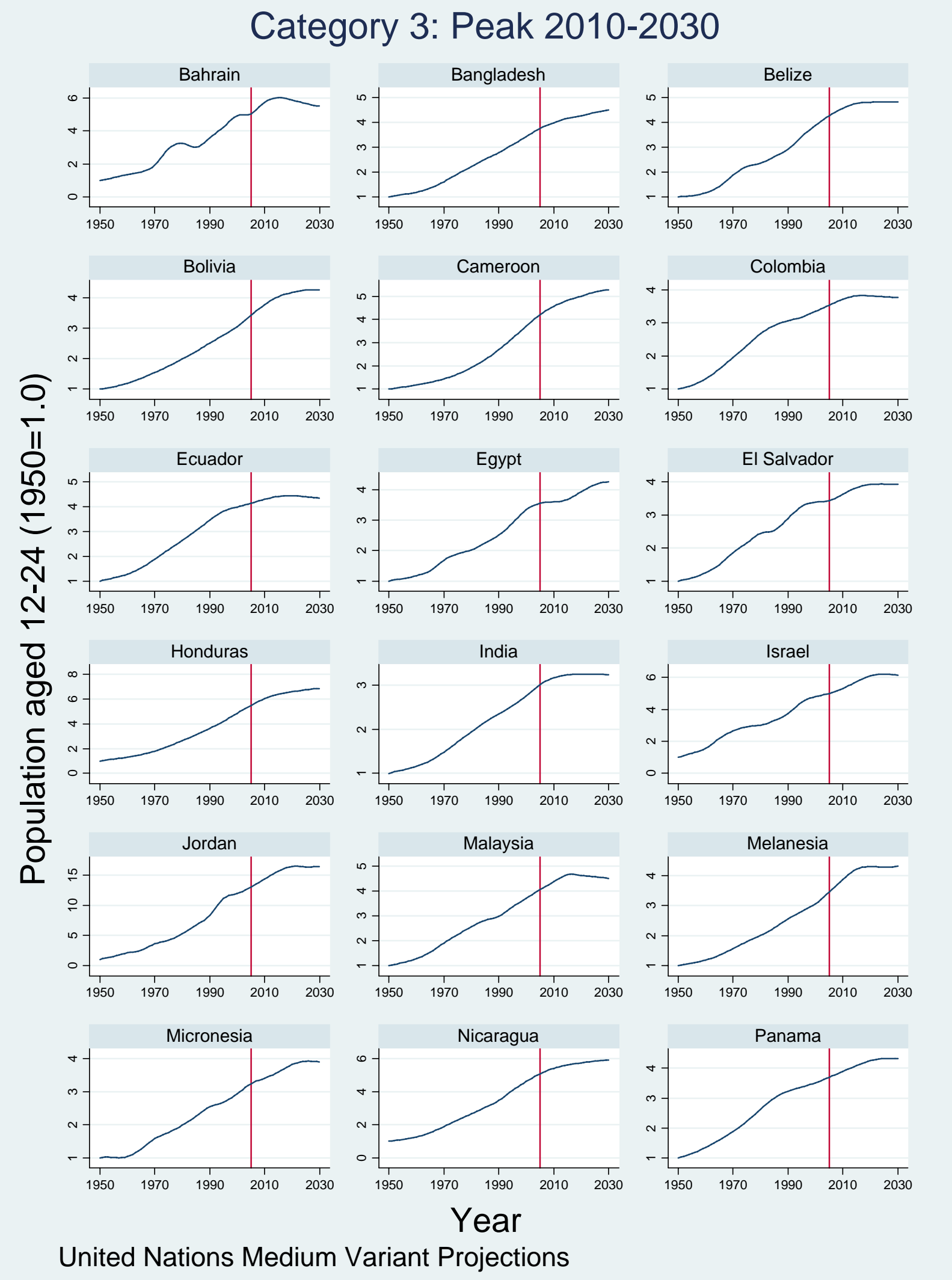




\section{Category 3: Peak 2010-2030}
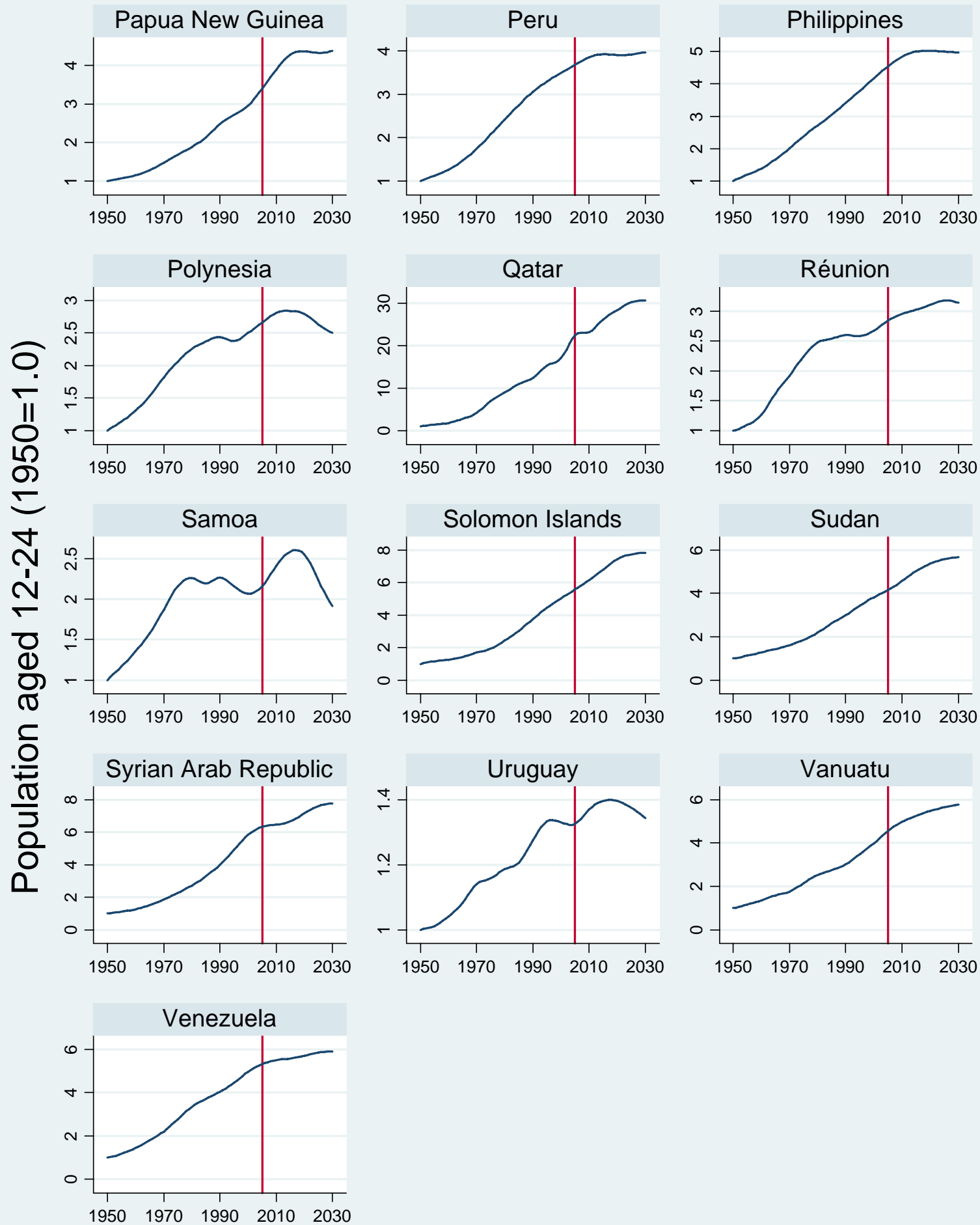

Year
United Nations Medium Variant Projections 


\section{Category 4: Peak after 2030}
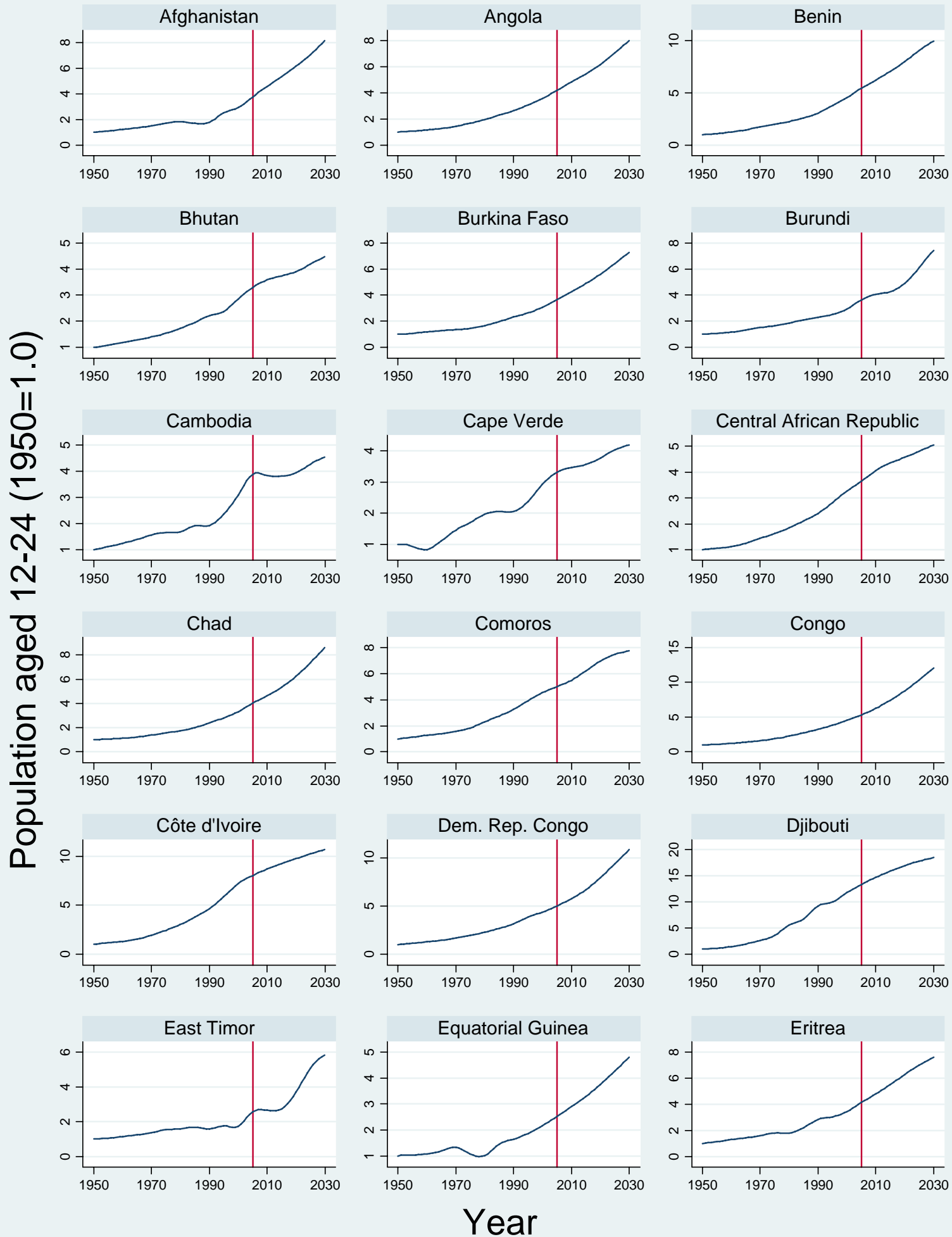

United Nations Medium Variant Projections 


\section{Category 4: Peak after 2030}
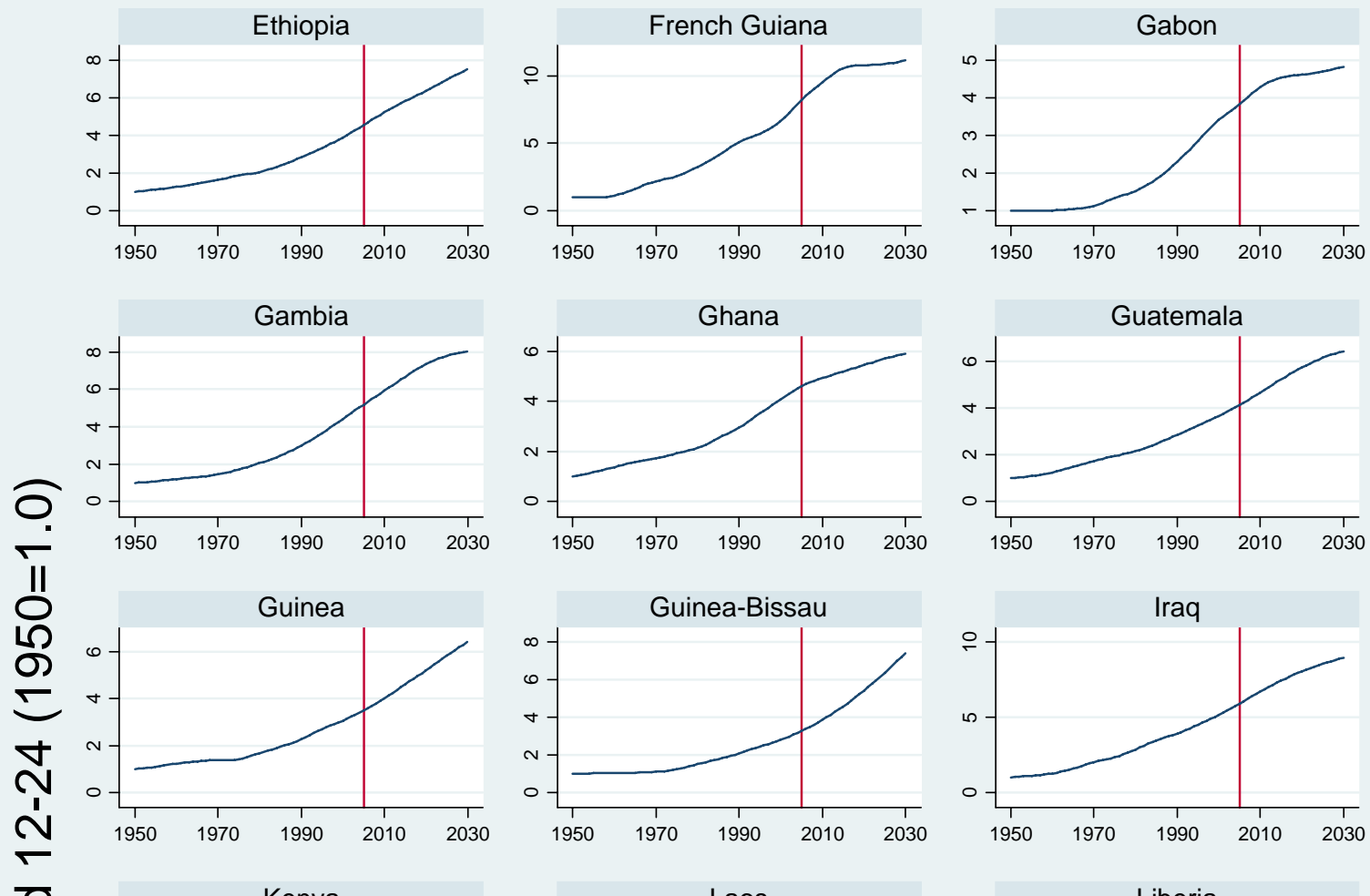

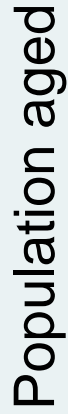
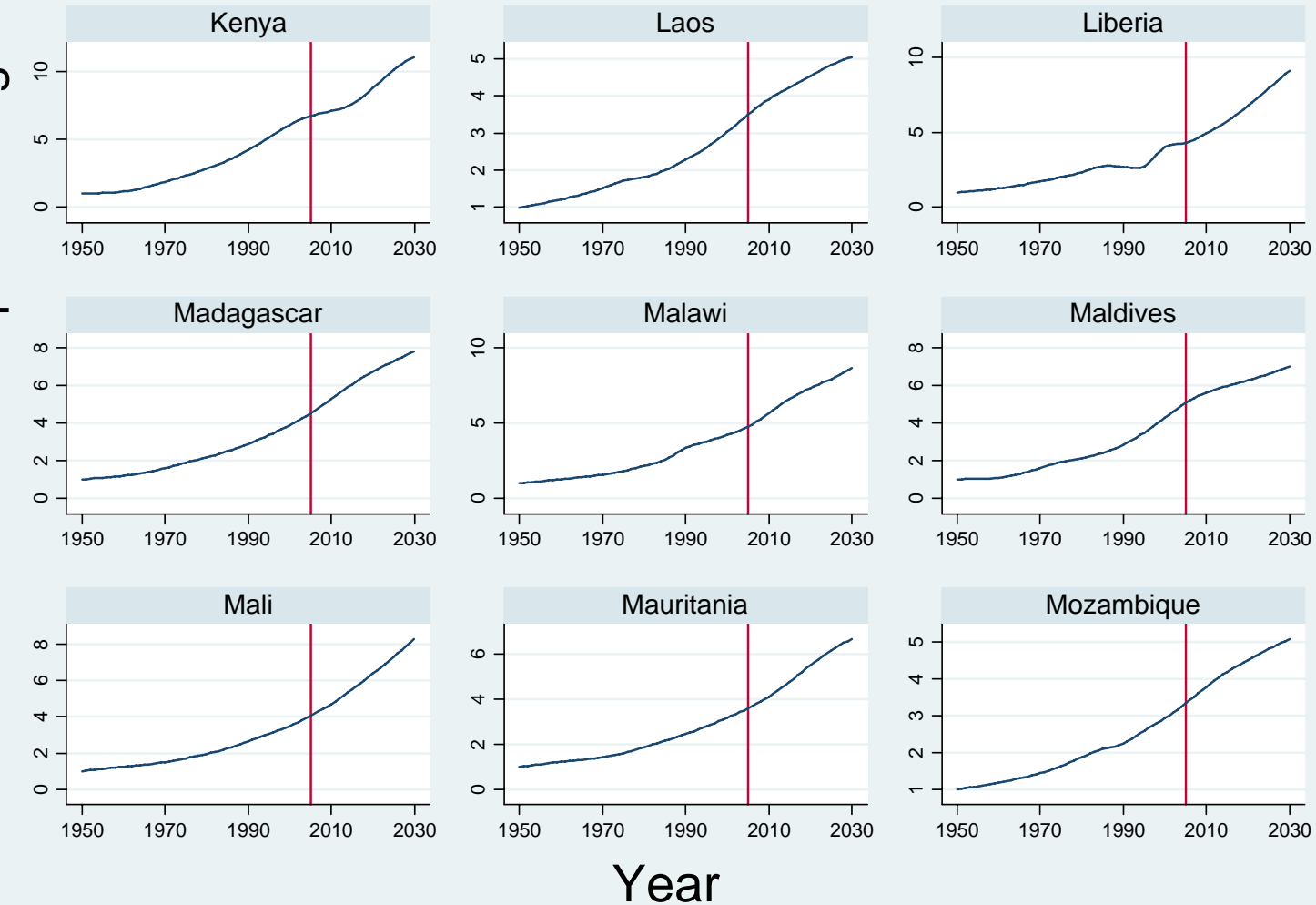

United Nations Medium Variant Projections 


\section{Category 4: Peak after 2030}
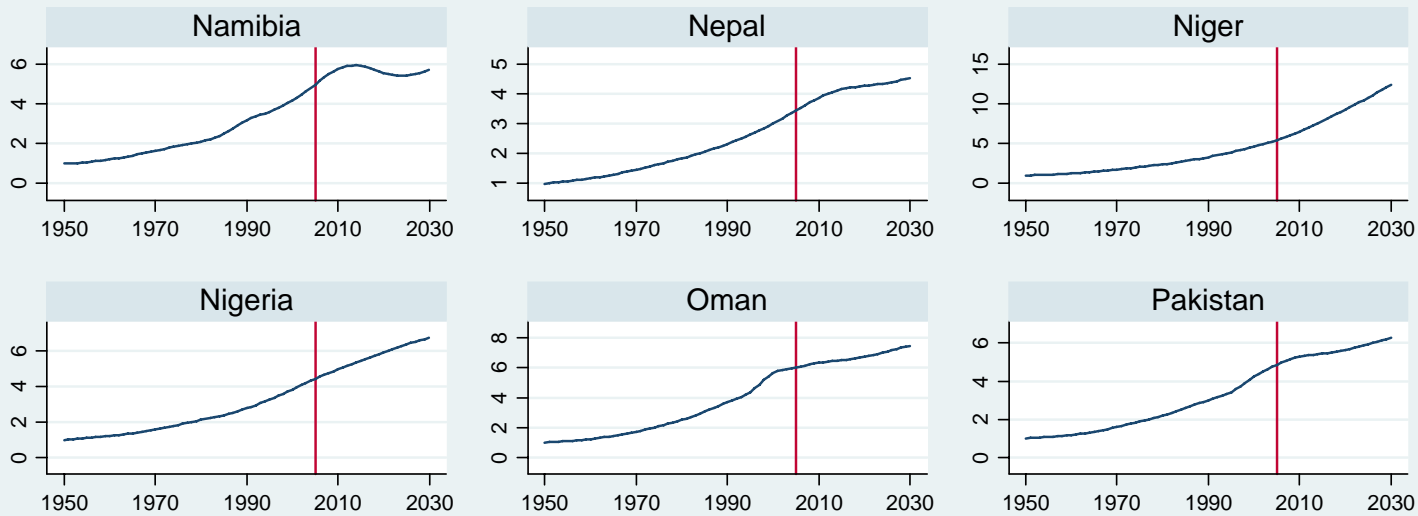

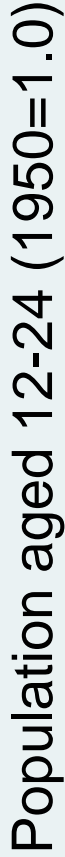
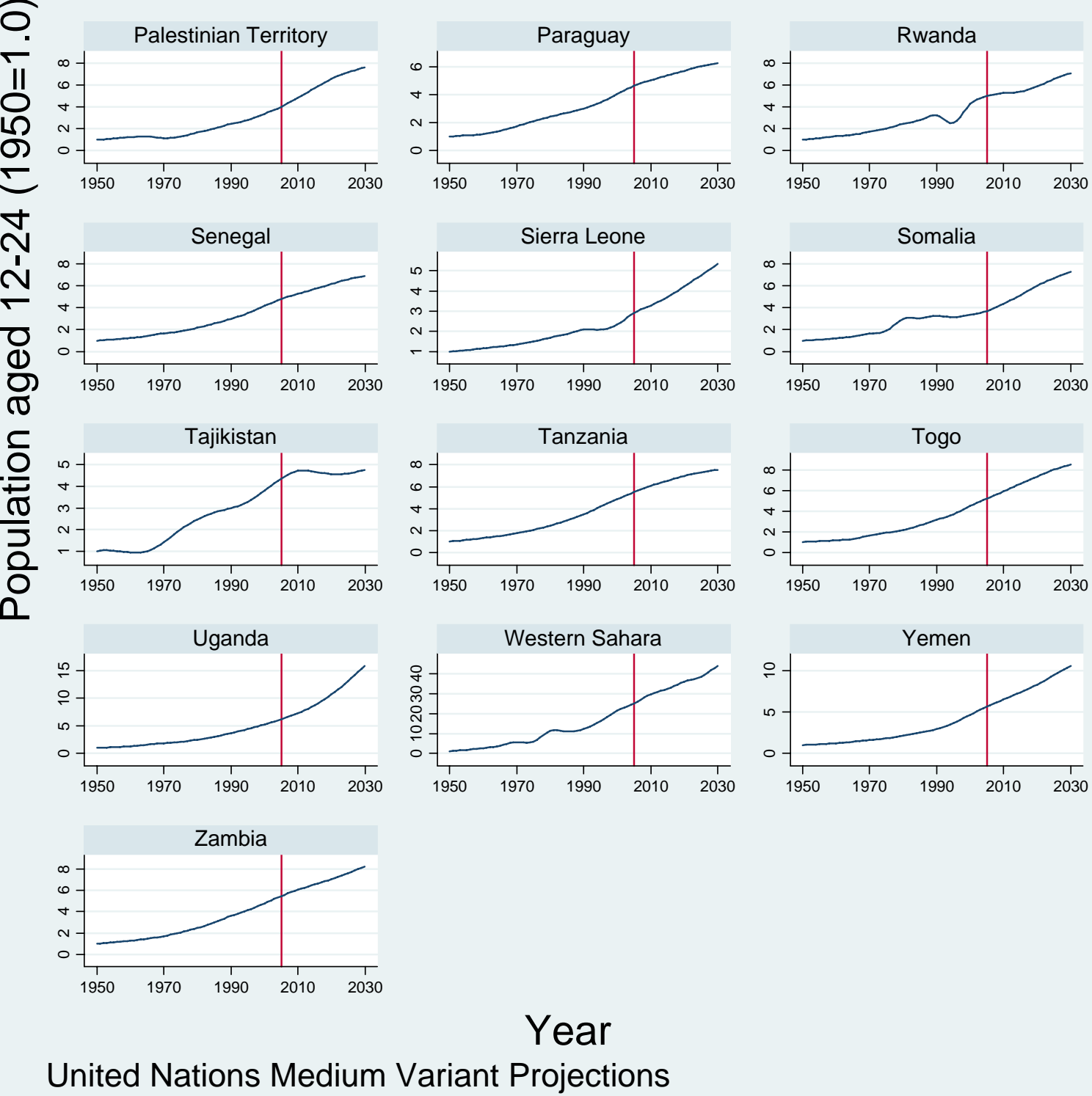